\title{
Impact of patient and public involvement on enrolment and retention in clinical trials: systematic review and meta-analysis
}

Check for updates

${ }^{1}$ Health Experiences Research Group, Nuffield Department of Primary Care Health Sciences, University of Oxford, Oxford

OX2 6GG, UK

${ }^{2}$ National Institute for Health Research (NIHR) Oxford

Biomedical Research Centre

(BRC), John Radcliffe Hospital,

Oxford, UK

${ }^{3}$ Balearic Islands Health

Research Institute (IdISBa),

Palma de Mallorca, Spain

${ }^{4}$ Primary Care Research Unit

of Mallorca, Balearic Islands

Health Service, Palma de

Mallorca, Spain

${ }^{5}$ Ciber de Epidemiologia y Salud

Publica (CIBERESP), Madrid,

Spain

${ }^{6}$ York Trials Unit, Department of Health Sciences, University of York, York, UK

${ }^{7}$ Nuffield Department of Primary Care Health Sciences, University of Oxford, Oxford, UK

${ }^{8}$ University of the West of

England, Bristol, UK

${ }^{9}$ Oxford Academic Health

Science Network, Oxford, UK

Correspondence to: I Crocker joanna.crocker@phc.ox.ac.uk

(ORCID 0000-0002-8223-0349)

Additional material is published online only. To view please visit

the journal online.

Cite this as: $B M J$ 2018;363:k4738 http://dx.doi.org/10.1136/bmj.k4738

Accepted: 30 October 2018

\author{
Joanna C Crocker, ${ }^{1,2}$ Ignacio Ricci-Cabello, ${ }^{3,4,5}$ Adwoa Parker, ${ }^{6}$ Jennifer A Hirst, ${ }^{7}$ Alan Chant, ${ }^{2}$ \\ Sophie Petit-Zeman, ${ }^{2}$ David Evans, ${ }^{8}$ Sian Rees $^{9}$
}

\section{ABSTRACT}

OBJECTIVE

To investigate the impact of patient and public involvement (PPI) on rates of enrolment and retention in clinical trials and explore how this varies with the context and nature of PPI.

DESIGN

Systematic review and meta-analysis.

\section{DATA SOURCES}

Ten electronic databases, including Medline, INVOLVE Evidence Library, and clinical trial registries.

\section{ELIGIBILITY CRITERIA}

Experimental and observational studies quantitatively evaluating the impact of a PPI intervention, compared with no intervention or non-PPI intervention(s), on participant enrolment and/or retention rates in a clinical trial or trials. PPI interventions could include additional non-PPI components inseparable from the PPI (for example, other stakeholder involvement).

\section{DATA EXTRACTION AND ANALYSIS}

Two independent reviewers extracted data on enrolment and retention rates, as well as on the context and characteristics of PPI intervention, and assessed risk of bias. Random effects meta-analyses were used to determine the average effect of PPI interventions on enrolment and retention in clinical trials: main analysis including randomised studies only, secondary analysis adding non-randomised studies, and several exploratory subgroup and sensitivity analyses.

RESULTS

26 studies were included in the review; 19 were eligible for enrolment meta-analysis and five for retention meta-analysis. Various PPI interventions

\section{WHAT IS ALREADY KNOWN ON THIS TOPIC}

Patient and public involvement (PPI) in clinical trials has the potential to improve rates of enrolment and retention of participants

PPI may help by improving trial design, optimising recruitment and retention strategies and patient-facing materials, or directly approaching potential participants

Whether, when, or by how much, PPI affects rates of enrolment and retention of participants is not known

\section{WHAT THIS STUDY ADDS}

The nature of PPI interventions and the impact of these on trial enrolment and retention vary widely between studies

On average, PPI interventions seem to modestly but significantly increase the odds of participant enrolment

The impact of PPI on retention rates is less clear and requires further primary research evaluating PPI interventions that specifically target retention were identified with different degrees of involvement, different numbers and types of people involved, and input at different stages of the trial process. On average, PPI interventions modestly but significantly increased the odds of participant enrolment in the main analysis (odds ratio 1.16, 95\% confidence interval and prediction interval 1.01 to 1.34 ). Non-PPI components of interventions may have contributed to this effect. In exploratory subgroup analyses, the involvement of people with lived experience of the condition under study was significantly associated with improved enrolment (odds ratio 3.14 v 1.07; $P=0.02$ ). The findings for retention were inconclusive owing to the paucity of eligible studies (odds ratio $1.16,95 \%$ confidence interval 0.33 to 4.14 ), for main analysis).

\section{CONCLUSIONS}

These findings add weight to the case for PPI in clinical trials by indicating that it is likely to improve enrolment of participants, especially if it includes people with lived experience of the health condition under study. Further research is needed to assess which types of PPI work best in particular contexts, the cost effectiveness of PPI, the impact of PPI at earlier stages of trial design, and the impact of PPI interventions specifically targeting retention.

\section{SYSTEMATIC REVIEW REGISTRATION}

PROSPERO CRD42016043808.

\section{Introduction}

Poor recruitment and retention of patients in trials are major sources of research inefficiency because they delay the delivery of research, inflate its costs, and can lead to biased findings. ${ }^{12}$ The top inefficiency in the conduct of trials from recruitment of the first participant to publication of results is failure to meet recruitment targets. ${ }^{3}$ Directors of UK clinical trials units have identified "research into methods to boost recruitment in trials" and "methods to minimise attrition" as the top two priorities for trials methodology research. ${ }^{4}$ In the UK, only $56 \%$ of trials funded by the Health Technology Assessment programme recruit their originally specified target sample size, with $32 \%$ receiving an extension. ${ }^{5} 6$ Several initiatives aimed at improving recruitment and retention in clinical trials have been established, including the MRC START research programme and Trial Forge. ${ }^{78}$ Recruitment and retention interventions identified as meriting formal evaluation include patient and public involvement (PPI). ${ }^{9}$

In the UK, PPI (also known as "public involvement") has been defined as "research being carried out 'with' or 'by' members of the public (including patients 
and carers) rather than 'to', 'about' or 'for' them.”10 Trials in the UK have experienced a recent surge in PPI activity, partly because the National Institute for Health Research (NIHR) now expects active PPI in the research it funds. ${ }^{11}$ Patients and members of the public are primarily involved in agenda setting, steering committees, ethical review, protocol development, and piloting. ${ }^{12}$ Many different types of involvement exist, from one person to many people or whole patient organisations, from one-off involvement in a particular aspect of the trial (for example, reviewing draft information for patients or recruiting participants from their communities) to involvement throughout the trial (for example, as members of a trial steering committee), and from involvement with no decision making power (for example, as advisers) to involvement in decision making as equal partners.

Two broad arguments are made for involving patients and members of the public in health research: the moral argument (those affected by, or paying for, research should have a say in what and how it is done) and the consequentialist argument (PPI should improve the quality, efficiency, and impact of research). Because clinical trialists and funders are steeped in a predominantly quantitative, evidence based culture, the consequentialist argument for PPI in clinical trials (for example, that it increases participant enrolment rates) is likely to play an important role in the adoption of meaningful PPI as routine, widespread practice. Hypotheses about how PPI could increase enrolment rates include greater access to potential participants, improved information sheets, more patient centred trial design, more relevant research questions, and peer endorsement of research. ${ }^{13-16}$ One observational study of 114 trials reported a doubled odds of successful recruitment associated with "consumer input," but this did not attain statistical significance (odds ratio 2.00, 95\% confidence interval 0.36 to 10.05$).{ }^{17} \mathrm{~A}$ more recent observational study reported a statistical association between PPI and success of recruitment among UK mental health research studies, ${ }^{13}$ but many potential confounding factors could not be controlled for, and information about the nature of PPI in the included studies was lacking. Exploring the effectiveness of PPI practices to improve recruitment and retention of trial participants has been identified as one of the top research priorities for PPI in trials. ${ }^{18}$

This review aimed to measure the impact of PPI interventions on recruitment (specifically participant enrolment) and retention in clinical trials. A secondary objective was to explore how this impact varies according to context (for example, patient population, recruitment setting, trial treatment/intervention) and the nature of the PPI intervention (for example, activities, involvement model, and other PPI characteristics).

\section{Methods}

\section{Searches}

Our systematic literature review followed the PRISMA statement. ${ }^{19}$ We did a systematic electronic search in the following databases (last updated October 2017): Medline, Science Citation Index, Social Science Citation Index, Embase, PsychINFO, Cochrane Library, CINAHL, and Health Expectations journal. We constructed the search strategy by combining keywords within four topic domains: clinical trials, PPI, enrolment or retention of participants, and potential outcomes/change (see appendix 1). In addition to the electronic database search, we searched the INVOLVE Evidence Library for any papers pertaining to the impact of public involvement on health or public health research, ${ }^{20}$ as well as the ClinicalTrials.gov and WHO ICTRP clinical trial registries.

\section{Screening and study selection}

We conceptualised PPI as a complex intervention, ${ }^{21}$ involving human behaviours and often multiple interactive components. We included papers that quantitatively evaluated the impact of a PPI intervention, compared with no intervention or another non-PPI intervention, on enrolment and/or retention rates in a clinical trial or trials in any patient population (see eligibility criteria in table 1 for further details). We defined "PPI intervention" as an intervention that was, or included as an active component, any form of PPI consistent with the INVOLVE definition of public involvement: "research being carried out 'with' or 'by' members of the public rather than 'to', 'about' or 'for' them," where the term public includes patients, potential patients, carers, and people who use health and social care services, as well as people from organisations that represent people who use services. ${ }^{10}$ This included interventions not necessarily labelled or conceptualised as "PPI" by the study authors (for example, user testing, peer recruitment, and community based participatory research). We included interventions in which PPI was integrated with additional components inseparable from the PPI (such as involvement of other stakeholders) because this is consistent with the way patients are often involved in practice (for example, being part of an advisory group). Hereafter, we refer to such components as "non-PPI components" of interventions.

A review restricted to randomised controlled trials would give an incomplete summary of the impact of PPI, as many types of PPI interventions (for example, patient involvement in the early stages of trial design) are not amenable to randomisation; we therefore included non-randomised as well as randomised evaluations, with a plan for assessing risk of bias. We accepted all non-randomised study designs (provided there was a direct comparison group), including non-randomised controlled trials, controlled and uncontrolled before-after studies, and observational studies. Comparison groups were patients unexposed to the PPI intervention (for example, before its introduction) or patients exposed to an alternative intervention with no PPI (for example, recruitment via healthcare professionals). The evaluation did not have to be the study authors' primary research question. We put no limits on publication date or language. 


\begin{tabular}{|c|c|}
\hline Parameter & Eligibility criteria \\
\hline Population & Potential clinical trial participants in any patient population \\
\hline Intervention & $\begin{array}{l}\text { A trial methodology intervention that was, or included as an active component, any of kind PPI consistent with the INVOLVE definition of public involvement: } \\
\text { "research being carried out 'with' or 'by' members of the public rather than 'to', 'about' or 'for' them." }{ }^{10} \text { The term "public" includes patients, potential patients, } \\
\text { carers, and people who use health and social care services, as well as people from organisations that represent people who use services. The PPI contributor(s) } \\
\text { had to be either a patient, a carer, or a lay member of the public; research or healthcare professionals with the health condition under investigation were } \\
\text { included as PPI, but research or healthcare professionals only sharing a characteristic with the target population other than health condition (eg, ethnicity, sex, } \\
\text { age) were excluded. Qualitative research was included as a form of patient or public consultation, as this was previously deemed PPI in an INVOLVE report of } \\
\text { impact of PPI. }{ }^{16} \text { However, as qualitative research is excluded from many definitions of PPI, a sensitivity analysis without this type of study was done }\end{array}$ \\
\hline Comparator & $\begin{array}{l}\text { No intervention or another trial methodology intervention with no PPI. Studies with no direct comparison group were excluded (eg, those comparing enrolment } \\
\text { and/or retention rates against what might be expected for that patient population) }\end{array}$ \\
\hline Outcome & $\begin{array}{l}\text { Enrolment and/or retention rate, defined as the proportion of potential participants enrolled and the proportion of enrolled participants retained, respectively. } \\
\text { Enrolment included giving consent to take part or being randomised to the trial. Studies that assessed hypothetical participation or willingness to participate } \\
\text { in clinical trials, rather than actual enrolment in a trial, were excluded. Retention included adherence to a treatment programme and/or follow-up procedures. } \\
\text { At the start of data extraction for the meta-analyses, for pragmatic reasons a decision was taken to exclude studies with no appropriate enrolment rate } \\
\text { denominator (eg, enrolment reported as absolute numbers rather than rates). This led to the retrospective exclusion of some studies that had been included } \\
\text { during initial screening }\end{array}$ \\
\hline Context & $\begin{array}{l}\text { Clinical trial or trials, defined by the World Health Organization as "any research study that prospectively assigns human participants or groups of humans to one } \\
\text { or more health-related interventions to evaluate the effects on health outcomes." Interventions include but are not restricted to drugs, cells and other biological } \\
\text { products, surgical procedures, radiological procedures, devices, behavioural treatments, process of care changes, preventive care, etc. This definition includes } \\
\text { phase I to phase IV trials. }{ }^{22} \text { For inclusion in the review, the primary outcome had to be a measure of health status; studies of trials with a behavioural or other } \\
\text { non-clinical primary outcome were excluded }\end{array}$ \\
\hline Study design & $\begin{array}{l}\text { Non-randomised (including observational) studies as well as randomised studies were included, as randomisation would not be practical for many PPI } \\
\text { interventions }\end{array}$ \\
\hline
\end{tabular}

Initially, one reviewer (JC) screened all titles and abstracts for potentially eligible papers and subsequently assessed full text papers against the eligibility criteria. Another reviewer (SR) supervised this process and provided advice when there was uncertainty about eligibility. Later, we received funding for a second reviewer (IRC) to independently screen all records in addition to JC. At the end of this process, JC and IRC compared their results in terms of studies included and excluded. Discrepancies were discussed and the opinion of a third reviewer (AP) was sought when necessary to achieve consensus. We contacted authors to provide further information when confirmation of eligibility was needed.

AP and IRC also did forwards and backwards citation searches by hand searching reference lists of included studies and review articles and using the "cited by" function in Scopus. Any potentially eligible papers were double screened for eligibility by JC.

\section{Data extraction}

Using a standardised data extraction form in Microsoft Access, one of three reviewers (JC, AP, or IRC) extracted qualitative information from each paper about the context of the trial, the nature of PPI interventions, and the nature and findings of evaluations. This form was piloted and revised by JC and AP in the early stages. Two reviewers (JC and IRC) then independently extracted quantitative data from included papers on the primary outcomes (enrolment and retention), context, and PPI intervention into a standardised Microsoft Excel spreadsheet for the meta-analyses. For enrolment, we extracted the number of people invited, approached, or reached during the recruitment period (denominator) and the number who consented to take part in the clinical trial (numerator). We included the proxy denominator "total number of participants," where the intervention targeted a subgroup within the trial population (such as a minority ethnic group or specific geographical region) and the evaluation compared subgroup proportions with and without the intervention. For retention, we extracted the number of people who consented to take part (denominator) and the number who adhered to the trial protocol and/or completed follow-up for the longest period of time investigated by the authors (numerator). We chose the context and intervention variables a priori (table 2) because we considered them to be potentially influential on enrolment and retention outcomes, they are sometimes or often reported in study publications, and, if categorical, they could be split into no more than two or three categories (owing to the small overall sample size). This is consistent with recommendations that systematic reviews of complex interventions include typologies of the structural characteristics of the intervention and, where few or no typologies exist, that face validity for categorisation be provided by experts working in the field. ${ }^{23}$ We considered theories of change underpinning interventions to be potentially important, but we could not categorise them appropriately for inclusion in this analysis. We are doing a realist analysis on the same sample of studies to shed light on the underlying theory and mechanisms of impact of the included interventions (to be published separately).

Discrepancies between the two data extractors (JC and IRC) were discussed, and the opinion of a third reviewer (AP) was sought if necessary to achieve consensus. We sought additional or accompanying papers where necessary to obtain the data we needed (for example, papers describing the contextual clinical trial or the development of the intervention) and contacted authors to provide further information when insufficient data were reported in available papers. 


\begin{tabular}{|c|c|c|c|}
\hline Variable category & Variable & Format & Description/additional information \\
\hline Outcomes data & $\begin{array}{l}\text { Enrolment rate } \\
\text { denominator }\end{array}$ & $\begin{array}{l}\text { Pre-eligibility or } \\
\text { post-eligibility screening }\end{array}$ & $\begin{array}{l}\text { An intervention might increase the number of recruits, but not necessarily the number of } \\
\text { eligible recruits, if enrolment was measured before screening for eligibility occurred. Where both } \\
\text { pre-screening and post-screening enrolment figures were provided by the authors, both were } \\
\text { extracted but only the pre-eligibility figure was used in the primary meta-analysis as this spans a } \\
\text { greater period of the recruitment process. Subgroup analyses tested whether a difference existed } \\
\text { between pre-eligibility and post-eligibility enrolment findings }\end{array}$ \\
\hline \multirow[t]{3}{*}{ Contextual data } & Trial recruitment setting & $\begin{array}{l}\text { Healthcare, community, or } \\
\text { mixed (both settings) }\end{array}$ & "Healthcare" means participants were recruited via contact or association with a healthcare service \\
\hline & Trial intervention type & $\begin{array}{l}\text { Simple, complex, or } \\
\text { multiple }\end{array}$ & $\begin{array}{l}\text { "Simple" included drugs, other biological products, and medical devices. "Complex" included } \\
\text { surgical procedures and behavioural, psychological, educational, and health service interventions. } \\
\text { "Multiple" means that trials of both types of interventions were included in the study }\end{array}$ \\
\hline & $\begin{array}{l}\text { PPI in choosing research } \\
\text { question/topic }\end{array}$ & Yes or no & $\begin{array}{l}\text { PPI in choosing the research question or topic might improve enrolment owing to increased } \\
\text { relevance/importance to the target population. If not reported in the paper or accompanying } \\
\text { papers, and if study authors did not respond to requests for further information, it was assumed that } \\
\text { the answer was "no" }\end{array}$ \\
\hline \multirow[t]{7}{*}{$\begin{array}{l}\text { PPI intervention } \\
\text { characteristics }\end{array}$} & Timing/activity & $\begin{array}{l}\text { (1) Designing recruitment } \\
\text { or retention strategy. (2) } \\
\text { Developing patient-facing } \\
\text { information. (3) Directly } \\
\text { approaching/recruiting or } \\
\text { retaining participants }\end{array}$ & $\begin{array}{l}\text { Timing of the start of PPI intervention/first PPI activity. Earlier involvement might lead to greater } \\
\text { improvements for enrolment/retention. "Patient-facing information" included paper and online } \\
\text { materials and verbal messaging }\end{array}$ \\
\hline & $\begin{array}{l}\text { No of above activities } \\
\text { targeted by PPI } \\
\text { intervention (1-3) }\end{array}$ & 1,2 , or 3 & More extensive involvement might lead to greater improvements for enrolment/retention \\
\hline & $\begin{array}{l}\text { PPI intervention chosen/ } \\
\text { designed specifically to } \\
\text { increase enrolment or } \\
\text { retention }\end{array}$ & Yes or no & An intervention chosen or designed with this specific purpose may be more effective \\
\hline & PPI model & $\begin{array}{l}\text { One-off, intermittent, or } \\
\text { full team membership }\end{array}$ & $\begin{array}{l}\text { "One-off"=time limited, single phase, or single task (eg, a focus group). "Intermittent"=involved } \\
\text { periodically during the life of the trial (eg, an ongoing advisory group). "Full team membership"=PPI } \\
\text { contributors considered part of the research team (eg a grant co-applicant, co-investigator, research } \\
\text { partner, or employed recruiter) }\end{array}$ \\
\hline & $\begin{array}{l}\text { No of PPI contributors } \\
\text { involved }\end{array}$ & $1-2$ or $\geq 3$ & $\begin{array}{l}\text { A group of PPI contributors may provide more diverse perspectives than } 1 \text { or } 2 \text { individuals, the latter } \\
\text { being common practice in UK trial steering committees }\end{array}$ \\
\hline & $\begin{array}{l}\text { Lived experience of } \\
\text { condition under study }\end{array}$ & Yes or no & $\begin{array}{l}\text { At least one PPI contributor had lived experience (as patient or carer) of the health condition being } \\
\text { targeted by the trial. If study authors did not indicate that lay/public contributors were patients or } \\
\text { had lived experience of the target condition, and did not respond to requests for clarification, it was } \\
\text { assumed that the answer was "no" }\end{array}$ \\
\hline & $\begin{array}{l}\text { PPI visible to potential } \\
\text { trial participants }\end{array}$ & Yes or no & $\begin{array}{l}\text { This means that potential trial participants would have known about the PPI, either through direct } \\
\text { interaction with PPI contributors or from information about their involvement in the trial }\end{array}$ \\
\hline
\end{tabular}

\section{Risk of bias assessment}

Two reviewers (JC and IRC) independently assessed the risk of bias of the studies included in meta-analyses by using the Cochrane Risk of Bias tool for randomised studies and the ROBINS-I tool for non-randomised studies (with pre-specified potential confounding domains of time, funder, and patient population). ${ }^{2425}$ Discrepancies were discussed and a third reviewer consulted if necessary to achieve consensus. The studies were assessed for risk of bias in relation to our review question, not the study authors' primary research question (which often differed from ours, particularly for the non-randomised studies).

\section{Meta-analyses}

The only criterion for carrying out meta-analyses was the availability of sufficient outcomes. We took the view that any amount of statistical heterogeneity would be acceptable, ${ }^{26}$ and we considered that, even in the presence of high heterogeneity, an estimate of the average effect of PPI interventions across studies and the statistical significance of this effect were worth reporting. We did two separate meta-analyses to determine the average impact of PPI interventions on enrolment and retention. We combined the numbers of participants enrolled and retained with and without PPI by using a random effects DerSimonian and Laird meta-analysis to report odds ratios. We used the Hartung-Knapp-Sidik-Jonkman variance correction to calculate $95 \%$ confidence intervals reflecting the uncertainty in heterogeneity estimates. ${ }^{27-29}$ We examined statistical heterogeneity by using the $\mathrm{I}^{2}$ statistic and by calculating approximate 95\% prediction intervals (which indicate a predicted range for the true effect of a PPI intervention in an individual study) ${ }^{30}$ using methods reported by Higgins et al. ${ }^{31}$ Because of high methodological and statistical heterogeneity across non-randomised studies, we made a post-hoc decision to present findings from randomised studies only as our main analysis. We then did a secondary analysis including non-randomised studies as well as randomised studies. Where multiple non-PPI recruitment strategies had been used within a non-randomised study, we pooled the data for comparison with the PPI recruitment strategy. Where multiple PPI interventions had been compared within a study, we included both interventions as separate comparisons in the meta-analysis and split numbers of participants in the comparator group equally across the two intervention arms. 
We did pre-planned subgroup analyses on all included studies (randomised and non-randomised combined) to explore the influence of context and characteristics of the PPI intervention on the association between PPI interventions and enrolment rates and to investigate sources of heterogeneity (table 2). We used univariable meta-regression to determine whether differences between subgroups were statistically significant.

We did sensitivity analyses on both the main analysis (randomised studies only) and the secondary analysis (randomised and non-randomised studies combined). These excluded studies at high risk of bias, studies with small sample sizes $(\mathrm{n}<100)$, PPI interventions that included additional non-PPI components, PPI interventions that were formal qualitative research (and therefore not universally classified as PPI), and studies using a proxy denominator to measure enrolment rate (see table 2).

We used Peters' test to examine small study effects. $^{32} 33$ As only two included studies investigated the cost per participant enrolled of PPI versus nonPPI interventions, we did not do a meta-analysis for this outcome. We used Stata 14.0SE for all analyses, with a threshold of $\mathrm{P}<0.05$ to determine statistical significance.

\section{Patient and public involvement}

The idea for this review emerged from meetings with an advisory panel for JC's research fellowship in

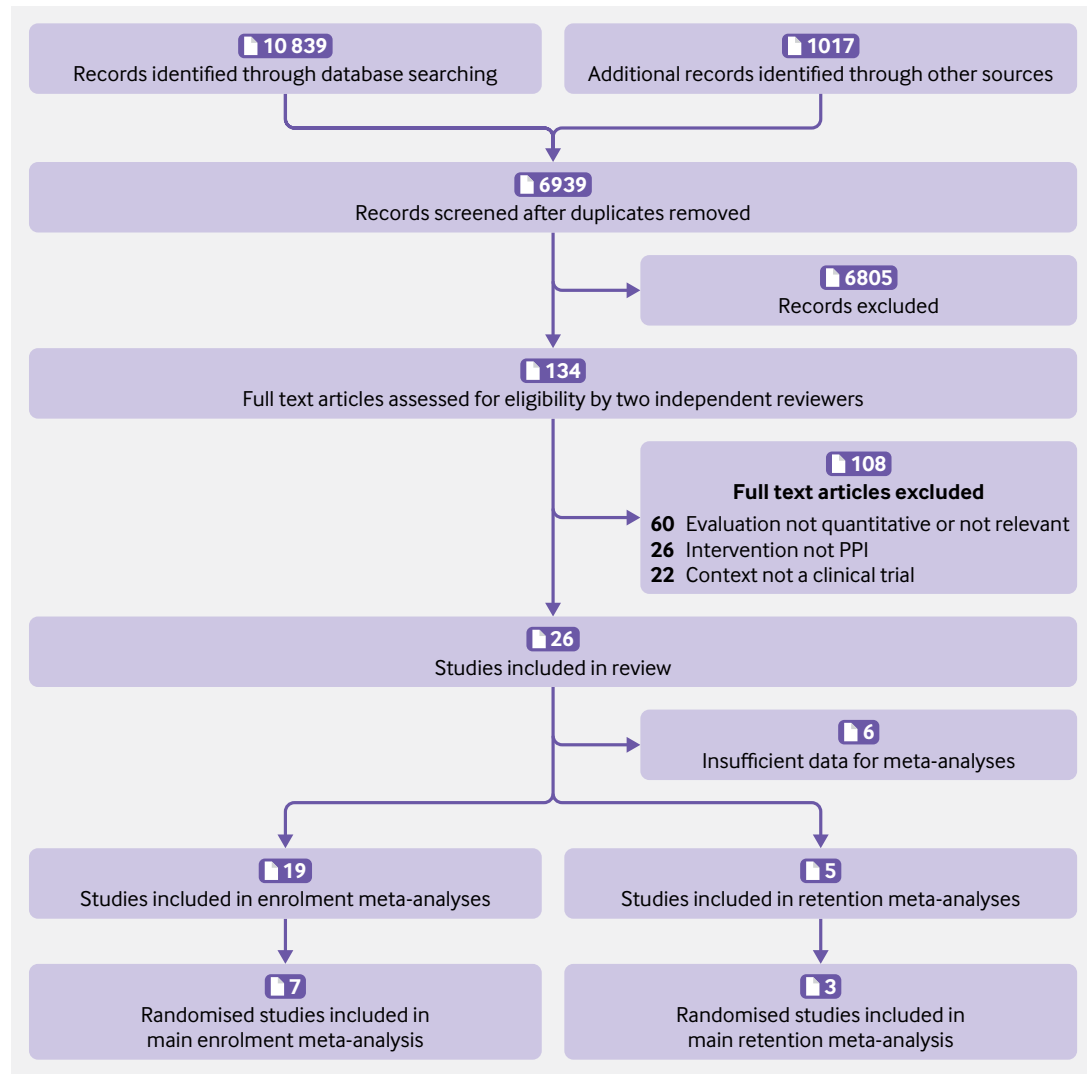

Fig 1 | PRISMA flow diagram of records/studies included at each stage of screening and in final meta-analyses. $\mathrm{PPI}=$ patient and public involvement
PPI impact assessment, which included two patient partners (including author AC). The patient partners were involved in the group to ensure that the research was relevant to, and informed by the perspectives of, patients and members of the public. They were chosen because of their long term experience of involvement in health research and their interest in impact assessment. The decision to do this review was in part due to our patient partners' desire to quantitatively assess the impact of PPI, particularly on recruitment of patients to clinical trials, because "a trial that recruits more quickly will ultimately benefit patients more quickly." While the review was underway, one patient partner (MO) retired and a third (RH) joined the group.

The patient partners provided input at six advisory group meetings and email correspondence in between meetings. As well as helping to decide on the review question, they helped to decide on our definition of PPI, which contextual and intervention characteristics to explore and how to categorise them, and which potential confounding factors to focus on in the risk of bias assessments. In addition to influencing these decisions, their enthusiasm and belief in the importance of this work helped to maintain the lead author's motivation through what was a challenging piece of work. Working in partnership with patients has been a very positive experience for the researchers in the team, and we have not identified any negative effects on the research. Our current patient partners (AC and $\mathrm{RH}$ ) report multiple positive aspects of their involvement, including being interested in the topic and endorsing its importance, feeling welcomed and respected as part of the project team, and feeling that their contributions are valued and responded to. Negative aspects have included difficulty following the conversation and contributing during teleconference meetings (sometimes necessary because of the long geographical distance between $\mathrm{RH}$ and the lead author) and having only a limited understanding of the mathematics of the meta-analysis.

\section{Results \\ Characteristics of studies included in systematic review}

Our search results yielded 11856 records. After excluding duplicates, two independent reviewers screened 6939 titles and abstracts and assessed 134 full text articles for eligibility. Twenty six studies met the criteria for inclusion in the review (fig 1).

Table 3, table 4, and table 5 show the detailed characteristics of all included studies. Most were conducted in the USA or the UK, and together they covered a wide range of clinical topic areas and trial interventions. The PPI interventions were also diverse. Patients and/or members of the public were involved in different activities: eight studies involved patients or lay people in designing recruitment and retention strategies (for example, as community partners, members of a community advisory board, or focus group participants), ${ }^{34} 4151556669757612$ 
studies involved patients or lay people in developing patient-facing information (for example, patient information sheets, multimedia and online interventions, recruitment advertisements, and verbal messaging), ${ }^{394143454953585961636678}$ and 10 studies involved patients or lay people in directly recruiting or retaining participants (for example, hiring lay/ community workers or asking existing participants to refer friends/relatives). ${ }^{34} 364647516065677279$ The extent of involvement ranged from one patient advocate acting as a panellist in a one-off educational seminar for recruiting clinicians, ${ }^{59}$ to more than 80 people helping to develop a patient friendly online trials registry, ${ }^{41} 42$ or community partners initiating and leading their own recruitment strategies. ${ }^{5176}$ Many intended purposes of involvement also existed, including increasing trust between communities and researchers, ${ }^{34} 4651606579$ improving the quality and acceptability of patient-facing information or recruitment messages, ${ }^{39} 4143 \quad 53 \quad 6163 \quad 78$ accessing potential participants via existing participants, ${ }^{36} 67$ and increasing the cultural competence of the research among minority ethnic communities. ${ }^{364660676972757679}$ Many of the PPI interventions also included nonPPI components, such as the involvement of other stakeholders or experts, ${ }^{415861656975}$ or novel modes of information delivery that were not a direct consequence of the PPI. ${ }^{45} 536067727879$

\begin{tabular}{|c|c|c|c|}
\hline Study & Participants & Geographical setting & Clinical trial intervention(s)/treatment(s) \\
\hline Arean et al, $2003^{3435}$ & $\begin{array}{l}\text { People aged } \geq 65 \text { with symptoms of } \\
\text { depression, anxiety, and at-risk drinking }\end{array}$ & San Francisco, USA & $\begin{array}{l}\text { Three types of psychosocial intervention for depression; social service mode } \\
\text { of care delivered in community geriatric medicine clinic }\end{array}$ \\
\hline Chlebowski et al, $2010^{3638}$ & $\begin{array}{l}\text { Healthy white men aged } \geq 55 \text { years and } \\
\text { healthy black men aged } \geq 50 \text { years }\end{array}$ & USA (multisite) & Selenium and vitamin $\mathrm{E} v$ placebo for prevention of prostate cancer \\
\hline Cockayne et al, $2017^{3940}$ & $\begin{array}{l}\text { People aged }>65 \text { who had attended routine } \\
\text { podiatry appointment within previous } 6 \\
\text { months }\end{array}$ & UK (multisite) & Podiatry intervention $v$ usual care for prevention of falls in older people \\
\hline Dear et al, $2012^{4142}$ & $\begin{array}{l}\text { Cancer patients consulting with their } \\
\text { physician }\end{array}$ & Australia (multisite) & Various (multiple trials included) \\
\hline Donovan et al, $2002^{4344}$ & $\begin{array}{l}\text { Men aged } 50-69 \text { years with localised } \\
\text { prostate cancer }\end{array}$ & UK (multisite) & $\begin{array}{l}\text { Surgery, radiotherapy, or monitoring for treatment of localised prostate } \\
\text { cancer }\end{array}$ \\
\hline Du et al, $2008^{45}$ & Patients aged 21-80 years with lung cancer & Detroit, USA & $\begin{array}{l}\text { Various therapeutic and non-therapeutic interventions (multiple trials } \\
\text { included) }\end{array}$ \\
\hline Ford et al, $2004^{46}$ & African-American men aged 55-74 years & USA (multisite) & Screening for prostate, lung, and colorectal cancers \\
\hline Fouad et al, $2014^{4748}$ & $\begin{array}{l}\text { Minority ethnic, low income women with } \\
\text { low grade cervical cytological abnormalities }\end{array}$ & $\begin{array}{l}\text { Jefferson County, AL, } \\
\text { USA }\end{array}$ & $\begin{array}{l}\text { Immediate colposcopy, triage, or conservative management of cytological } \\
\text { diagnosis of atypical squamous cells of undetermined significance }\end{array}$ \\
\hline Guarino et al, $2006^{49} 50$ & $\begin{array}{l}\text { Gulf War veterans with fatigue, } \\
\text { musculoskeletal pain, and/or cognitive } \\
\text { complaints }\end{array}$ & USA (multisite) & $\begin{array}{l}\text { Cognitive behavioural therapy, aerobic exercise, or both } v \text { usual care for } \\
\text { treatment of Gulf War veterans' illnesses }\end{array}$ \\
\hline Horowitz et al, $2009^{5152}$ & Adults with pre-diabetes & East Harlem, NY, USA & Community based, peer led weight loss programme to prevent diabetes \\
\hline Hutchison et al, $2007^{5354}$ & $\begin{array}{l}\text { Patients with colorectal, breast, or lung } \\
\text { cancer and clinically eligible for entry into } \\
\text { randomised treatment trial }\end{array}$ & Glasgow, UK & Cancer treatment $v$ control/standard treatment or best supportive care \\
\hline Iliffe et al, $2013^{55-57}$ & $\begin{array}{l}\text { Patients with moderate to severe } \\
\text { Alzheimer's disease who had been treated } \\
\text { with donepezil for } \geq 3 \text { months }\end{array}$ & UK (multisite) & $\begin{array}{l}\text { Continue donepezil, discontinue donepezil, discontinue donepezil and start } \\
\text { memantine, or continue donepezil and start memantine, for treatment of } \\
\text { moderate to severe Alzheimer's disease }\end{array}$ \\
\hline Kass et al, $2009^{58}$ & $\begin{array}{l}\text { Patients with cancer referred for evaluation } \\
\text { with oncologist regarding possible } \\
\text { participation in early phase clinical trial }\end{array}$ & USA (multisite) & Cancer treatments (various early phase clinical trials) \\
\hline Kimmick et al, $2005^{59}$ & Patients aged $\geq 65$ years with cancer & USA (multisite) & Cancer treatments (various trials) \\
\hline MacEntee et al, $2002^{60}$ & $\begin{array}{l}\text { Community dwelling older people with } \\
\text { history of poor oral care }\end{array}$ & Vancouver, Canada & Antibacterial mouthwash to reduce tooth loss \\
\hline Man et al, $2015^{6162}$ & Adult patients with depression & UK (multisite) & $\begin{array}{l}12 \text { month telehealth intervention } v \text { usual general practitioner care for } \\
\text { treatment of depression }\end{array}$ \\
\hline Martin et al, $2013^{6364}$ & $\begin{array}{l}\text { New mothers who self identified as black/ } \\
\text { African-American or Hispanic/Latina }\end{array}$ & New York City, USA & $\begin{array}{l}\text { Behavioural educational intervention to prevent postpartum depression } \\
\text { among black and Latina women }\end{array}$ \\
\hline Moinpour et al, $2000^{65}$ & Healthy men aged $\geq 55$ years & USA (multisite) & Finasteride $v$ placebo to prevent prostate cancer \\
\hline Porter et al, $2016^{66}$ & $\begin{array}{l}\text { Patients with cancer registered at one } \\
\text { clinical centre }\end{array}$ & Ohio, USA & Cancer treatments (various trials) \\
\hline Sanders et al, $2009^{6768}$ & $\begin{array}{l}\text { Women aged } \geq 70 \text { years at high risk of falls } \\
\text { or fractures }\end{array}$ & Victoria, Australia & Vitamin $\mathrm{D} v$ placebo to prevent fractures \\
\hline Tenorio et al, $2011^{69-71}$ & Men and women aged $55-74$ years & Denver, USA & $\begin{array}{l}\text { Screening } v \text { routine medical care to reduce mortality from prostate, lung, } \\
\text { colorectal, and ovarian cancers }\end{array}$ \\
\hline Tenorio et al, $2014^{72-74}$ & $\begin{array}{l}\text { People who had smoked } \geq 30 \text { pack years of } \\
\text { cigarettes }\end{array}$ & Denver, USA & $\begin{array}{l}\text { Computed tomography } v \times \text { ray screening to diagnose and reduce mortality } \\
\text { from lung cancer }\end{array}$ \\
\hline Vicini et al, $2011^{75}$ & $\begin{array}{l}\text { Patients with cancer diagnosed and treated } \\
\text { at one hospital }\end{array}$ & Michigan, USA & $\begin{array}{l}\text { Interventions focused on cancer treatment, prevention, detection, symptom } \\
\text { management, or cancer control (various clinical trials) }\end{array}$ \\
\hline Vincent et al, $2013^{7677}$ & $\begin{array}{l}\text { Spanish speaking Latinos of Mexican origin } \\
\text { at high risk of diabetes }\end{array}$ & Arizona, USA & Community based weight loss programme to prevent diabetes \\
\hline Wallace et al, $2006^{78}$ & Men with early stage prostate cancer & Toronto, Canada & $\begin{array}{l}\text { Surgical prostatectomy } v \text { interstitial radiation for treatment of early stage } \\
\text { prostate cancer }\end{array}$ \\
\hline Wisdom et al, $2002^{79}$ & $\begin{array}{l}\text { African-Americans with type } 2 \text { diabetes } \\
\text { diagnosed after age } 30 \text { years }\end{array}$ & Michigan, USA & Self management programme $v$ usual care for treatment of diabetes \\
\hline
\end{tabular}




\begin{tabular}{|c|c|c|c|}
\hline Study & Primary aim of intervention & PPI component(s) & Other (non-PPI) components* \\
\hline $\begin{array}{l}\text { Arean et al, } \\
2003^{3435}\end{array}$ & $\begin{array}{l}\text { To improve recruitment and } \\
\text { retention of older minority } \\
\text { adults to trial }\end{array}$ & $\begin{array}{l}\text { All recruitment and study procedures } \\
\text { were discussed at bimonthly consumer } \\
\text { advisory board meetings. A community } \\
\text { member was trained by research staff to } \\
\text { recruit and screen participants }\end{array}$ & $\begin{array}{l}\text { A range of other "consumer centred" } \\
\text { strategies including face-to-face } \\
\text { recruitment, personalised mailings, and } \\
\text { in-home interviews. }\end{array}$ \\
\hline $\begin{array}{l}\text { Chlebowski et al, } \\
2010^{36-38}\end{array}$ & $\begin{array}{l}\text { To improve rates of consent } \\
\text { to randomisation in trial }\end{array}$ & $\begin{array}{l}\text { Women already participating in a large } \\
\text { health research project were asked to } \\
\text { recruit their husbands }\end{array}$ & None \\
\hline $\begin{array}{l}\text { Cockayne et al, } \\
2017^{3940}\end{array}$ & $\begin{array}{l}\text { To improve trial recruitment } \\
\text { rates }\end{array}$ & $\begin{array}{l}\text { Two different PPI interventions: "bespoke } \\
\text { user-tested" PIS: formal user testing of } \\
\text { PIS by } 30 \text { members of public; "template } \\
\text { developed PIS": historical non-bespoke } \\
\text { user testing; PPI group reviewed PIS and } \\
\text { gave feedback. }\end{array}$ & $\begin{array}{l}\text { "Bespoke user tested" PIS: design input } \\
\text { by researchers and commercial company. } \\
\text { "Template developed PIS": design input } \\
\text { by experienced researchers }\end{array}$ \\
\hline $\begin{array}{l}\text { Dear et al, } \\
2012^{4142}\end{array}$ & $\begin{array}{l}\text { To improve proportion } \\
\text { of patients with whom } \\
\text { participation in any clinical } \\
\text { trial was discussed }\end{array}$ & $\begin{array}{l}\text { Consumer input into design and content } \\
\text { of consumer friendly online cancer trials } \\
\text { registry }\end{array}$ & $\begin{array}{l}\text { Online cancer trials registry developed } \\
\text { by web company with input from staff } \\
\text { at Australian New Zealand Clinical Trials } \\
\text { Registry }\end{array}$ \\
\hline
\end{tabular}

$\begin{array}{lll}\text { Donovan et al, } & \text { To improve rates of consent } & \text { In-depth interviews with potential } \\ 2002^{4344} & \text { to randomisation in trial } & \begin{array}{l}\text { participants who had been invited to } \\ \text { take part }\end{array}\end{array}$

\begin{tabular}{ll}
\hline Du et al, 2008 & $\begin{array}{l}\text { To improve clinical trial } \\
\text { enrolment at a large cancer } \\
\text { centre }\end{array}$ \\
\hline Ford et al, 2004 & \\
& $\begin{array}{l}\text { To improve rates of } \\
\text { recruitment to trial }\end{array}$ \\
\hline Fouad et al, & $\begin{array}{l}\text { To improve rates of retention } \\
\text { in trial and adherence to } \\
\text { scheduled appointments }\end{array}$ \\
\end{tabular}

Presentation of a view on clinical trials from the perspectives of patients with diverse ethnic backgrounds and characteristics (in addition to standard information)

Church based project sessions including Screening was conducted by consent taking, plus enhanced recruitment letter from a prominent local African-American man (arm C of trial) $2014^{4748}$ scheduled appointment

Community health advisor model, in which community members served as a link between participants and study investigators and provided additional support to participants, in addition to standard retention activities

\begin{tabular}{ll}
\hline $\begin{array}{l}\text { Guarino et al, } \\
2006^{4950}\end{array}$ & $\begin{array}{l}\text { To improve informed } \\
\text { consent (participants' } \\
\text { understanding of the trial) }\end{array}$ \\
\hline $\begin{array}{l}\text { Horowitz et al, } \\
2009^{5152}\end{array}$ & $\begin{array}{l}\text { To increase recruitment of } \\
\text { black and Latina people } \\
\text { into trial }\end{array}$
\end{tabular}

Focus group of Gulf War veterans reviewed and edited PIS

Qualitative analysis of interviews by researchers. Other qualitative research methods, including interviews with recruiters and analysis of audio recorded recruitment appointments. Findings were used to change patient information and train recruiters

Video developed by National Cancer Institute

Positively changing patients' knowledge of and attitudes to clinical trials

Women participating in clinical studies are altruistic, and their husbands share this quality and are willing to participate in a similar clinical trial Improving the quality and appearance of patient information sheets

Improving consumer knowledge and understanding of clinical trials; enabling patients to search for local trials they might like to join; providing decision support for patients considering joining a trial

Uncovering problems with information and communication during recruitment to the trial African-American interviewers

\section{None}

Two different PPI interventions:

"public events" recruitment strategy, in which community members recruited participants at public events; "partner led" recruitment strategy, in which community advocates designed and led recruitment strategy

\begin{tabular}{ll}
\hline Hutchison et al, & To improve recruitment to \\
$2007^{5354}$ & cancer clinical trials
\end{tabular}

\section{In addition to standard written}

information, patients were given access

to audiovisual information designed with input from two cancer patients and presented by a local actress

\begin{tabular}{lll}
\hline $\begin{array}{l}\text { Iliffe et al, } \\
2013^{55-57}\end{array}$ & $\begin{array}{l}\text { To explore why, in some } \\
\text { areas, recruitment rates had } \\
\text { been below what was hoped }\end{array}$ & $\begin{array}{l}\text { Two focus groups with patients with } \\
\text { neurological conditions and carers, lead- } \\
\text { ing to changes in recruitment strategy }\end{array}$ \\
\hline Kass et al, 200958 & $\begin{array}{l}\text { To improve patients' } \\
\text { understanding of early } \\
\text { phase clinical trials }\end{array}$ & $\begin{array}{l}\text { Intervention included video clips of five } \\
\text { actors portraying patients who decided } \\
\text { to enrol in a clinical trial (three) or not } \\
\text { to enrol (two). The scripts were based }\end{array}$ \\
& & on real patient narratives. The overall \\
& & intervention was modified using feedback \\
& & from 18 cancer patients and survivors \\
Kimmick et al, & To improve recruitment of & Educational intervention for physicians, \\
$2005^{59}$ & older people by physicians & including a case discussion seminar with \\
to cancer treatment trials & a patient advocate panellist
\end{tabular}

Development of audiovisual patient information was led by professionals

Improving patients' understanding of clinical trials, including randomisation

None

Intervention was a self directed, narrated computer based presentation, including suggested questions and video clips of oncologists. Oncologists also gave feedback on the intervention

The intervention also included standard information, an educational symposium, educational materials, a list of available protocols for use, and a monthly email and mail reminders for one year (with no patient input)
Enabling physicians to discuss com mon problems in geriatric oncology with a panel of experts dentifying the cause of recruitmen problems and suggesting remedial actions

Improving patients' understanding of the purpose and benefits of early phase clinical trials 


\begin{tabular}{|c|c|c|c|c|}
\hline Study & Primary aim of intervention & PPI component(s) & Other (non-PPI) components* & Authors' proposed mechanism \\
\hline $\begin{array}{l}\text { MacEntee et al, } \\
2002^{60}\end{array}$ & $\begin{array}{l}\text { To improve recruitment of } \\
\text { ethnic minorities }\end{array}$ & $\begin{array}{l}\text { At least one contact person in each } \\
\text { community centre served as a volunteer } \\
\text { interpreter and cultural liaison between } \\
\text { potential recruits and researchers }\end{array}$ & $\begin{array}{l}\text { Recruitment by researchers via commu- } \\
\text { nity centres, including posters and an } \\
\text { introductory lecture about the trial }\end{array}$ & $\begin{array}{l}\text { Using active and trusted members of } \\
\text { the community to communicate with } \\
\text { potential recruits }\end{array}$ \\
\hline $\begin{array}{l}\text { Man et al, } \\
2015^{6162}\end{array}$ & $\begin{array}{l}\text { To improve recruitment to } \\
\text { trial }\end{array}$ & $\begin{array}{l}\text { PIS underwent three rounds of user } \\
\text { testing with members of the public }\end{array}$ & $\begin{array}{l}\text { Input by experts in writing for patients } \\
\text { and graphic design (before user testing) }\end{array}$ & $\begin{array}{l}\text { Improving the readability and } \\
\text { presentation of patient information } \\
\text { sheets }\end{array}$ \\
\hline $\begin{array}{l}\text { Martin et al, } \\
2013^{6364}\end{array}$ & $\begin{array}{l}\text { To improve recruitment to } \\
\text { trial }\end{array}$ & $\begin{array}{l}\text { All women who refused to participate } \\
\text { in the trial were asked open ended } \\
\text { questions about their reasons for refusal. } \\
\text { The research team used this feedback to } \\
\text { improve their recruitment message }\end{array}$ & $\begin{array}{l}\text { Researchers analysed women's feedback } \\
\text { and made changes to the recruitment } \\
\text { message }\end{array}$ & $\begin{array}{l}\text { Identifying and overcoming barriers to } \\
\text { recruitment }\end{array}$ \\
\hline $\begin{array}{l}\text { Moinpour et al, } \\
2000^{65}\end{array}$ & $\begin{array}{l}\text { To improve recruitment of } \\
\text { minority ethnic men to the } \\
\text { trial }\end{array}$ & $\begin{array}{l}\text { "Enhanced minority recruitment } \\
\text { programme," included hiring African- } \\
\text { American and Hispanic recruiters, several } \\
\text { of whom were respected members in } \\
\text { their minority communities }\end{array}$ & $\begin{array}{l}\text { The enhanced minority recruitment } \\
\text { programme included multiple other } \\
\text { components such as special training in } \\
\text { minority recruitment for site staff and } \\
\text { consultation with experts in minority } \\
\text { recruitment }\end{array}$ & $\begin{array}{l}\text { Reducing the time taken to identify } \\
\text { potential participants, establish trust, } \\
\text { and introduce the trial }\end{array}$ \\
\hline Porter et al, $2016^{66}$ & $\begin{array}{l}\text { To achieve a } 40 \% \text { increase } \\
\text { in accrual to clinical trials } \\
\text { over a } 2 \text { year period }\end{array}$ & $\begin{array}{l}\text { The "comprehensive programme" } \\
\text { included the leadership team informally } \\
\text { reaching out to patients at the outset } \\
\text { and intermittently during the campaign } \\
\text { to increase accrual. A cancer survivor } \\
\text { was pictured and quoted on publicity } \\
\text { to encourage patients to enquire about } \\
\text { clinical trial opportunities }\end{array}$ & $\begin{array}{l}\text { The programme was multifaceted and } \\
\text { included tasking centre leadership with } \\
\text { increased oversight of the entire process } \\
\text { of patient accrual to trials, education of } \\
\text { all stakeholders, increased oversight of } \\
\text { the portfolio of clinical trials by disease } \\
\text { specific committees, and optimisation of } \\
\text { accrual operations and infrastructure }\end{array}$ & $\begin{array}{l}\text { Equipping all stakeholders } \\
\text { (patients, their families, nurses and } \\
\text { staff, physicians, disease specific } \\
\text { committees, and centre leadership) } \\
\text { with the necessary skills and } \\
\text { information to complete the clinical } \\
\text { trial accrual process }\end{array}$ \\
\hline $\begin{array}{l}\text { Sanders et al, } \\
2009^{6768}\end{array}$ & $\begin{array}{l}\text { To improve recruitment to } \\
\text { the trial }\end{array}$ & $\begin{array}{l}\text { "Word of mouth" recruitment strategy in } \\
\text { which the research team organised morn- } \\
\text { ing teas for participants and invited them } \\
\text { to bring a friend who could potentially } \\
\text { enrol in the trial }\end{array}$ & $\begin{array}{l}\text { The morning teas provided a social } \\
\text { opportunity for participants and potential } \\
\text { participants to meet researchers face } \\
\text { to face }\end{array}$ & $\begin{array}{l}\text { Giving participants a sense of } \\
\text { "belonging and ownership of the } \\
\text { project" and providing an opportunity } \\
\text { for the friend to enrol in the trial }\end{array}$ \\
\hline $\begin{array}{l}\text { Tenorio et al, } \\
2011^{69-71}\end{array}$ & $\begin{array}{l}\text { To improve recruitment of } \\
\text { Hispanic people to the trial }\end{array}$ & $\begin{array}{l}\text { A Hispanic community focus group, } \\
\text { including two lay people, advised on } \\
\text { recruitment strategies }\end{array}$ & $\begin{array}{l}\text { The community focus group included } \\
\text { healthcare and research professionals. } \\
\text { The recruitment strategy was also } \\
\text { informed by a literature review of factors } \\
\text { affecting recruitment of Hispanic people } \\
\text { to clinical trials }\end{array}$ & $\begin{array}{l}\text { Tailoring the recruitment plan to the } \\
\text { Hispanic community; identifying } \\
\text { and overcoming cultural barriers to } \\
\text { recruitment }\end{array}$ \\
\hline $\begin{array}{l}\text { Tenorio et al, } \\
2014^{72-74}\end{array}$ & $\begin{array}{l}\text { To improve recruitment of } \\
\text { Hispanic people to the trial }\end{array}$ & $\begin{array}{l}\text { Lay consultants from the Hispanic } \\
\text { community approached potential } \\
\text { participants }\end{array}$ & $\begin{array}{l}\text { Culturally tailored recruitment strategies } \\
\text { including use of bilingual Hispanic } \\
\text { staff, bilingual recruitment materials } \\
\text { and seminars, and announcements at } \\
\text { predominantly Hispanic churches }\end{array}$ & $\begin{array}{l}\text { Overcoming cultural barriers to } \\
\text { recruitment of Hispanic people; } \\
\text { maximising adherence to Hispanic } \\
\text { cultural norms }\end{array}$ \\
\hline Vicini et al, $2011^{75}$ & $\begin{array}{l}\text { To decrease ethnic minority } \\
\text { healthcare disparities and } \\
\text { increase representation of } \\
\text { ethnic minorities in cancer } \\
\text { clinical trials }\end{array}$ & $\begin{array}{l}\text { Minority outreach programme, } \\
\text { involving collaboration with community } \\
\text { based organisations from five major } \\
\text { ethnic/minority populations. Hospital } \\
\text { representatives worked with community } \\
\text { leaders to develop culturally competent } \\
\text { programmes, leading to a series of } \\
\text { forums presented within each ethnic } \\
\text { minority community }\end{array}$ & $\begin{array}{l}\text { The collaboration included hospital } \\
\text { representatives who were available at } \\
\text { recruitment forums to inform patients } \\
\text { about the clinical trials available at the } \\
\text { hospital }\end{array}$ & $\begin{array}{l}\text { Providing culture specific, bilingual } \\
\text { cancer education and information } \\
\text { on prevention and screening in a } \\
\text { culturally competent manner }\end{array}$ \\
\hline $\begin{array}{l}\text { Vincent et al, } \\
2013^{7677}\end{array}$ & $\begin{array}{l}\text { To increase recruitment and } \\
\text { retention in trial }\end{array}$ & $\begin{array}{l}\text { Catholic church partners suggested a } \\
\text { recruitment strategy based on healthy } \\
\text { living/diabetes prevention presentations } \\
\text { at the churches }\end{array}$ & None & $\begin{array}{l}\text { Minimising cultural and } \\
\text { contextual barriers to recruitment; } \\
\text { maximising positive relationships, } \\
\text { communication, trust, and respect, } \\
\text { which are particularly important when } \\
\text { working with Mexican Americans } \\
\end{array}$ \\
\hline $\begin{array}{l}\text { Wallace et al, } \\
2006^{78}\end{array}$ & $\begin{array}{l}\text { To improve patients' } \\
\text { understanding of the } \\
\text { treatment options and } \\
\text { facilitate accrual to trial }\end{array}$ & $\begin{array}{l}\text { During a } 90 \text { minute patient education } \\
\text { session (intervention), a prostate cancer } \\
\text { survivor and trial participant shared his } \\
\text { (positive) experience of clinical trials with } \\
\text { patients }\end{array}$ & $\begin{array}{l}\text { The patient education session also } \\
\text { included an informed consent video } \\
\text { and a joint presentation by a urologist } \\
\text { and radiation oncologist comparing } \\
\text { and contrasting their modalities and } \\
\text { introducing the concept of a randomised } \\
\text { controlled trial }\end{array}$ & $\begin{array}{l}\text { Providing balanced information } \\
\text { about the treatment options, thereby } \\
\text { increasing patients' acceptance of } \\
\text { randomisation }\end{array}$ \\
\hline $\begin{array}{l}\text { Wisdom et al, } \\
2002^{79}\end{array}$ & $\begin{array}{l}\text { To improve recruitment and } \\
\text { retention in trial }\end{array}$ & $\begin{array}{l}\text { Active recruitment of participants by faith } \\
\text { based organisations and churches in the } \\
\text { community }\end{array}$ & $\begin{array}{l}\text { As well as pastors, the study's principal } \\
\text { investigator also made regular } \\
\text { announcements from the pulpit }\end{array}$ & $\begin{array}{l}\text { Building trust, accessibility, caring, } \\
\text { reciprocity, and sensitivity, based on } \\
\text { two theoretical models to improve } \\
\text { recruitment of culturally diverse } \\
\text { populations and access to care }\end{array}$ \\
\hline
\end{tabular}

PIS=patient information sheet.

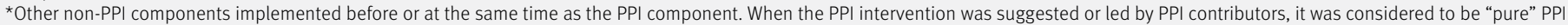
even if the suggested intervention included other non-PPI aspects. 


\section{Table 5 | Characteristics of evaluations included in review \\ Study Non-PPI comparison group}

Arean et al, $2003^{34} 35 \quad$ "Traditional" recruitment model consisting of gatekeeper referral and media advertisements with no design input from consumers

$\begin{array}{ll}\text { Chlebowski et al, } & \text { Mass mailing of invitation letters to potential } \\ 2010^{36-38} & \text { participants }\end{array}$

\begin{tabular}{ll}
\hline Cockayne et al, $2017^{3940}$ & $\begin{array}{l}\text { Original PIS developed for the trial, written } \\
\text { in accordance with the standard National } \\
\text { Research Ethics Service template }\end{array}$
\end{tabular}

Dear et al, $2012^{4142} \quad$ Usual approach to recruitment of trial participants, with no access to consumer friendly online trials registry

Donovan et al, $2002^{4344}$ Recruitment according to original trial protocol

\begin{tabular}{|c|c|}
\hline Du et al, $2008^{45}$ & $\begin{array}{l}\text { Standard care (first visit with medical } \\
\text { oncologist) with no access to video }\end{array}$ \\
\hline Ford et al, $2004^{46}$ & $\begin{array}{l}\text { Standard trial recruitment procedures at } \\
\text { health site; consent taken by mail; screening } \\
\text { conducted by African-American and white } \\
\text { interviewers (arm D of trial) }\end{array}$ \\
\hline Fouad et al, $2014^{4748}$ & $\begin{array}{l}\text { Standard retention activities (reminder calls, } \\
\text { cards, and incentives) }\end{array}$ \\
\hline Guarino et al, $2006^{4950}$ & Original PIS designed by researchers \\
\hline
\end{tabular}

Guarino et al, $2006^{4950}$ Original PIS designed by researchers

\begin{tabular}{ll}
\hline Horowitz et al, 20095152 & $\begin{array}{l}\text { Other recruitment strategies: clinical referral, } \\
\text { special recruitment events, and recruitment via } \\
\text { community based organisations }\end{array}$ \\
\hline Hutchison et al, 2007 5354 & $\begin{array}{l}\text { Standard trial specific written patient } \\
\text { information }\end{array}$ \\
\hline Iliffe et al, 2013 & $\begin{array}{l}\text { Original recruitment strategy before focus } \\
\text { groups }\end{array}$
\end{tabular}

\begin{tabular}{|c|c|c|c|c|}
\hline Kass et al, $2009^{58}$ & $\begin{array}{l}\text { Informational pamphlet developed by the } \\
\text { National Cancer Institute called "Taking part } \\
\text { in clinical trials: what cancer patients need to } \\
\text { know" }\end{array}$ & $\begin{array}{l}\text { Enrolment: proportion of patients invited to } \\
\text { take part in a clinical trial who subsequently } \\
\text { decided to enrol in the trial (self reported). } \\
\text { Retention: not assessed }\end{array}$ & $\begin{array}{l}\text { Enrolment: } 130 \text {; } \\
\text { retention: NA }\end{array}$ & $\begin{array}{l}\text { Randomised controlled } \\
\text { trial }\end{array}$ \\
\hline Kimmick et al, $2005^{59}$ & $\begin{array}{l}\text { Standard information only (periodic notification } \\
\text { of all existing trials and website access) }\end{array}$ & $\begin{array}{l}\text { Enrolment: proportion of older cancer patients } \\
\text { registered who were subsequently accrued to a } \\
\text { cancer treatment trial. Retention: not assessed }\end{array}$ & $\begin{array}{l}\text { Enrolment: } 3032 \text {; } \\
\text { retention: NA }\end{array}$ & $\begin{array}{l}\text { Randomised controlled } \\
\text { trial }\end{array}$ \\
\hline MacEntee et al, $2002^{60}$ & $\begin{array}{l}\text { Announcements in newspapers to attract } \\
\text { potential recruits }\end{array}$ & $\begin{array}{l}\text { Enrolment: proportion of initial responders who } \\
\text { were subsequently recruited to the trial; cost } \\
\text { per recruit. Retention: not assessed }\end{array}$ & $\begin{array}{l}\text { Enrolment: } 887 \text {; } \\
\text { retention: NA }\end{array}$ & Observational study \\
\hline Man et al, $2015^{6162}$ & $\begin{array}{l}\text { Standard information sheet designed by } \\
\text { researchers using National Research Ethics } \\
\text { Service guidelines }\end{array}$ & $\begin{array}{l}\text { Enrolment: proportion of patients who received } \\
\text { PIS and were subsequently randomised to trial. } \\
\text { Retention: not assessed }\end{array}$ & $\begin{array}{l}\text { Enrolment: } 1364 ; \\
\text { retention: NA }\end{array}$ & $\begin{array}{l}\text { Randomised controlled } \\
\text { trial }\end{array}$ \\
\hline Martin et al, $2013^{6364}$ & $\begin{array}{l}\text { Original recruitment message (before } \\
\text { intervention) }\end{array}$ & $\begin{array}{l}\text { Enrolment: proportion of women approached } \\
\text { who were subsequently randomised to trial. } \\
\text { Retention: not assessed }\end{array}$ & $\begin{array}{l}\text { Enrolment: } 668 \text {; } \\
\text { retention: NA }\end{array}$ & $\begin{array}{l}\text { Uncontrolled time } \\
\text { series }\end{array}$ \\
\hline Moinpour et al, $2000^{65}$ & $\begin{array}{l}\text { Original minority recruitment protocol (before } \\
\text { enhanced programme introduced) }\end{array}$ & $\begin{array}{l}\text { Enrolment: proportion of total participants (all } \\
\text { ethnicities) who were from ethnic minorities. } \\
\text { Retention: not assessed }\end{array}$ & $\begin{array}{l}\text { Enrolment: } 18882 \text {; } \\
\text { retention: NA }\end{array}$ & $\begin{array}{l}\text { Uncontrolled before- } \\
\text { after study }\end{array}$ \\
\hline Porter et al, $2016^{66}$ & $\begin{array}{l}\text { Original clinical trials accrual programme } \\
\text { (before comprehensive programme introduced) }\end{array}$ & $\begin{array}{l}\text { Enrolment: annual number of patient accruals, } \\
\text { accruals per active trial, and accrual rate } \\
\text { (number of patients accrued in a given } \\
\text { calendar year divided by number of new } \\
\text { analytical cases seen at the cancer centre for } \\
\text { that same year). Retention: not assessed }\end{array}$ & $\begin{array}{l}\text { Enrolment: } 35853 \text {; } \\
\text { retention: NA }\end{array}$ & $\begin{array}{l}\text { Uncontrolled time } \\
\text { series }\end{array}$ \\
\hline
\end{tabular}

Enrolment and retention outcomes assessed Total No of participants Evaluation design

Enrolment: proportion of potentially eligible Enrolment: 444;

Observational study

minorities identified who were subsequently

recruited to trial. Retention: proportion of

minority participants completing 3 month and

6 month follow-up assessment

Enrolment: proportion of men targeted for $\quad$ Enrolment: 60800; Non-randomised

recruitment who were subsequently enrolled in retention: NA controlled trial

trial; cost per participant enrolled. Retention:

not assessed

Enrolment: proportion of participants invited Enrolment: 6900;

Randomised controlled

who were subsequently randomised. Retention: retention: 193

trial

proportion of patients retained in the trial at 3

months after randomisation

Enrolment: proportion of eligible patients $\quad$ Enrolment: 340; Randomised controlled

consulting with a physician who subsequently retention: NA tria

self reported consent to take part in a trial.

Retention: not assessed

Enrolment: proportion of men invited who

subsequently consented to randomisation.

Retention: proportion of men who consented

to randomisation and subsequently accepted

their allocated treatment

Enrolment: proportion of patients who enrolled

in therapeutic/non-therapeutic trials after

visit with medical oncologist. Retention: not assessed

Enrolment: proportion of men contacted and

found eligible who were randomised to trial.

Retention: not assessed

$\begin{array}{ll}\text { Enrolment: } 155 ; & \text { Uncontrolled before- } \\ \text { retention: } 108 & \text { after study }\end{array}$

Enrolment: 126;

Randomised controlled trial

Enrolment: not assessed. Retention: proportion Enrolment: NA; of participants who attended all follow-up visits retention: 632

Randomised controlled Enrolment: proportion of patients invited who Enrolment: 2793 subsequently refused to take part in trial. Retention: proportion of participants missing any primary outcome data

\section{Enrolment: proportion of people approached} who were subsequently enrolled in the trial. Retention: not assessed

Enrolment: proportion of patients invited who were subsequently enrolled into a trial. Retention: not assessed

Enrolment: proportion of total participants

(all regions) recruited in intervention exposed regions before versus after intervention.

regions before versus a
Retention: not assessed

Enrolment: proportion of patients invited to

retention: 1092

Randomised controlled trial

Enrolment: 554:

Observational study

retention: NA

Enrolment: 173;

retention: NA

Randomised controlled

Enrolment: 200;

retention: NA

Controlled before-after study 


\begin{tabular}{|c|c|c|c|c|}
\hline Study & Non-PPI comparison group & Enrolment and retention outcomes assessed & Total No of participants & Evaluation design \\
\hline Sanders et al, $2009^{6768}$ & $\begin{array}{l}\text { "Targeted mail out” recruitment strategy } \\
\text { consisting of postal invitations to women } \\
\text { aged } \geq 70 \text { years listed on government agency } \\
\text { databases }\end{array}$ & $\begin{array}{l}\text { Enrolment: proportion of people invited } \\
\text { who were subsequently enrolled in the trial. } \\
\text { Retention: not assessed }\end{array}$ & $\begin{array}{l}\text { Enrolment: } 21600 \text {; } \\
\text { retention: NA }\end{array}$ & Observational study \\
\hline Tenorio et al, $2011^{69-71}$ & Recruitment plan for general population & $\begin{array}{l}\text { Enrolment: proportion of total participants (all } \\
\text { ethnicities) who were Hispanic before versus } \\
\text { after intervention. Retention: not assessed. }\end{array}$ & $\begin{array}{l}\text { Enrolment: } 21162 ; \\
\text { retention: NA }\end{array}$ & $\begin{array}{l}\text { Controlled before-after } \\
\text { study }\end{array}$ \\
\hline Tenorio et al, $2014^{72-74}$ & Recruitment plan for general population & $\begin{array}{l}\text { Enrolment: proportion of total participants } \\
\text { (all ethnicities) who were Hispanic in regions } \\
\text { exposed and not exposed to the intervention. } \\
\text { Retention: not assessed }\end{array}$ & $\begin{array}{l}\text { Enrolment: } 53053 \text {; } \\
\text { retention: NA }\end{array}$ & $\begin{array}{l}\text { Non-randomised } \\
\text { controlled trial }\end{array}$ \\
\hline Vicini et al, $2011^{75}$ & $\begin{array}{l}\text { Clinical trial accrual process before introduction } \\
\text { of the minority outreach programme }\end{array}$ & $\begin{array}{l}\text { Enrolment: annual number of minority patients } \\
\text { accrued, and as a proportion of total patients } \\
\text { accrued. Retention: not assessed }\end{array}$ & $\begin{array}{l}\text { Enrolment: } 3056 \text {; } \\
\text { retention: NA }\end{array}$ & $\begin{array}{l}\text { Uncontrolled time } \\
\text { series }\end{array}$ \\
\hline Vincent et al, $2013^{7677}$ & $\begin{array}{l}\text { Other recruitment strategies: flyers, posters, } \\
\text { and email announcements; community events; } \\
\text { health provider referrals }\end{array}$ & $\begin{array}{l}\text { Enrolment: proportion of people approached/ } \\
\text { referred who were subsequently enrolled in } \\
\text { trial. Retention: not assessed }\end{array}$ & $\begin{array}{l}\text { Enrolment: } 279 ; \\
\text { retention: NA }\end{array}$ & Observational study \\
\hline Wallace et al, $2006^{78}$ & $\begin{array}{l}\text { Eligible patients were individually approached } \\
\text { by a clinical research associate and invited to } \\
\text { view the informed consent video }\end{array}$ & $\begin{array}{l}\text { Enrolment: proportion of patients attending } \\
\text { educational session (intervention) or watching } \\
\text { informed consent video (comparator) who } \\
\text { subsequently consented to randomisation } \\
\text { Retention: not assessed }\end{array}$ & $\begin{array}{l}\text { Enrolment: } 290-324 \\
\text { (exact figure unknown } \\
\text { owing to data } \\
\text { discrepancies); } \\
\text { retention: NA }\end{array}$ & $\begin{array}{l}\text { Uncontrolled } \\
\text { before-after study }\end{array}$ \\
\hline Wisdom et al, $2002^{79}$ & $\begin{array}{l}\text { Recruitment from local healthcare system } \\
\text { (via mail) }\end{array}$ & $\begin{array}{l}\text { Enrolment: proportion of patients contacted } \\
\text { who subsequently enrolled in the trial. The } \\
\text { denominator used for the PPI exposed group } \\
\text { was the estimated number of faith based } \\
\text { organisation participants with diabetes, as the } \\
\text { comparator intervention (recruitment via health } \\
\text { system) targeted only patients with diabetes. } \\
\text { Retention: proportion of participants who } \\
\text { attended all seven intervention sessions }\end{array}$ & $\begin{array}{l}\text { Enrolment: } 1177 ; \\
\text { retention: } 102\end{array}$ & Observational study \\
\hline
\end{tabular}

$\mathrm{NA}=$ not applicable; $\mathrm{PPI}=$ patient and public involvement; $\mathrm{PIS}=$ patient information sheet.

Characteristics of studies included in meta-analyses We included 19 studies (21 PPI interventions) reporting data from 178921 participants in our enrolment meta-analyses and five studies (six PPI interventions) reporting data from 6520 participants in our retention meta-analyses. Table 6 shows the aggregate characteristics of these studies, including those used in subgroup and sensitivity analyses.

Six studies could not be included in the enrolment meta-analyses owing to insufficient data, despite our attempts to contact study authors and identify related papers. Three of these studies reported no significant impact of PPI interventions on enrolment, ${ }^{58} 5965$ and the other three studies reported an increase in enrolment rates associated with PPI interventions (statistical significance unknown) .66 $^{.6578}$

\section{Risk of bias of studies included in meta-analyses}

Of the eight randomised studies, only one was deemed to be at "high" risk of bias owing to missing outcome data, ${ }^{41}$ two had "some concerns," 4546 and five had "low" risk of bias. 3947495361 Of the 12 non-randomised studies, 11 were deemed to be at "serious" risk of

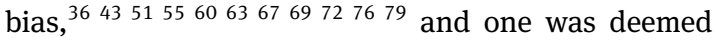
to be at "critical" risk of bias owing to potential uncontrolled confounding by patient population, time, or both. ${ }^{34}$ Often this was because the study was opportunistic-for example, comparing the success of different recruitment strategies-rather than designed specifically to evaluate the impact of PPI versus nonPPI on enrolment or retention.

\section{Impact of PPI interventions on enrolment} Individual study findings

Half $(11 / 21)$ of the PPI interventions included in our meta-analysis were associated with significantly higher enrolment rates compared with no PPI or non-PPI interventions, ${ }^{36} 43465155606367697276$ nine PPI interventions were not significantly associated with enrolment rate, ${ }^{35} 39414549515361$ and one PPI intervention was associated with significantly lower enrolment (odds ratio $0.41,95 \%$ confidence interval 0.23 to 0.72$).^{79}$ In this study, lay community members (faith based organisations) attempted to directly recruit African-Americans with diabetes to the trial; however, this yielded a lower enrolment rate than recruitment via the health system (non-PPI). The authors stated that this was not surprising, given "the nature of the provider-patient relationship" and because "African Americans may be less inclined to have their personal health history known by other members of their church congregation, given the stigma associated with chronic illnesses." ${ }^{\text {C9 }}$ Contrast this with Vincent et al's study, which showed the largest PPI effect size in our sample (odds ratio 13.48, 6.07 to 29.95): here, lay community members (Catholic church partners, some of whom shared a high risk of diabetes with the MexicanAmerican target population) initiated, co-designed, and co-delivered a recruitment strategy that was highly successful compared with strategies initiated by the researchers. ${ }^{77}$ (Note, however, that both of these outlying studies were non-randomised and judged to be at high risk of bias.) 


\begin{tabular}{|c|c|c|}
\hline Characteristic & Enrolment meta-analysis $(n=19)$ & Retention meta-analysis $(n=5)$ \\
\hline \multicolumn{3}{|l|}{ Evaluation features } \\
\hline No of people included & Range $126-60800$ (median 887) & Range 95-4599 (median 632) \\
\hline Year of publication & Range 2002-17 (median 2009) & Range 2002-17 (median 2006) \\
\hline \multicolumn{3}{|l|}{ Study design: } \\
\hline Randomised & 7 & 3 \\
\hline Non-randomised & 12 & 2 \\
\hline \multicolumn{3}{|l|}{ No of PPI interventions evaluated: } \\
\hline One & 17 & 4 \\
\hline Two & 2 & 1 \\
\hline \multicolumn{3}{|l|}{ Enrolment rate denominator: } \\
\hline Pre-eligibility screening & 12 & NA \\
\hline Post-eligibility screening & 6 & NA \\
\hline Unknown & 1 & NA \\
\hline \multicolumn{3}{|l|}{ Risk of bias*: } \\
\hline Low & 4 & 3 \\
\hline Some concerns & 2 & 0 \\
\hline High/serious & 12 & 1 \\
\hline Critical & 1 & 1 \\
\hline \multicolumn{3}{|l|}{ Context } \\
\hline \multicolumn{3}{|l|}{ Geographical setting: } \\
\hline Australia & 2 & 0 \\
\hline Canada & 1 & 0 \\
\hline UK & 5 & 1 \\
\hline USA & 11 & 4 \\
\hline \multicolumn{3}{|l|}{ Clinical trial intervention type: } \\
\hline Simple & 7 & 0 \\
\hline Complex & 9 & 5 \\
\hline Mixed/both & 3 & 0 \\
\hline \multicolumn{3}{|l|}{ Clinical trial recruitment setting: } \\
\hline Healthcare & 9 & 2 \\
\hline Community & 3 & 1 \\
\hline Mixed/both & 8 & 2 \\
\hline PPI in choosing research question/topic (context) & 3 & 0 \\
\hline \multicolumn{3}{|l|}{ PPI intervention features } \\
\hline \multicolumn{3}{|l|}{ PPI activity: } \\
\hline Recruitment/retention strategies & 6 & 1 \\
\hline Patient-facing information & 9 & 2 \\
\hline Direct recruitment/retention & 9 & 3 \\
\hline $\begin{array}{l}\text { PPI intervention was chosen/designed specifically to increase } \\
\text { recruitment or retention }\end{array}$ & 18 & 3 \\
\hline \multicolumn{3}{|l|}{ PPI model: } \\
\hline One-off & 10 & 3 \\
\hline Intermittent & 3 & 1 \\
\hline Full team membership & 6 & 1 \\
\hline \multicolumn{3}{|l|}{ No of PPI contributors involved: } \\
\hline One or two & 1 & 1 \\
\hline Three or more & 18 & 5 \\
\hline Unknown & 1 & 0 \\
\hline PPI contributor(s) had lived experience of condition under study & 12 & 0 \\
\hline PPI was visible to potential trial participants & 11 & 3 \\
\hline Intervention included some non-PPI components & 14 & 3 \\
\hline PPI was formal qualitative research & 1 & 0 \\
\hline \multicolumn{3}{|l|}{ Findings } \\
\hline \multicolumn{3}{|l|}{$\begin{array}{l}\text { Impact of PPI intervention on outcome (enrolment/retention rate) } \\
\text { relative to comparator: }\end{array}$} \\
\hline Significantly higher enrolment/retention & 11 & 1 \\
\hline No significant difference in enrolment/retention & 8 & 4 \\
\hline Significantly lower in enrolment/retention & 1 & 0 \\
\hline \multicolumn{3}{|c|}{$\begin{array}{l}\text { NA=not applicable; } \mathrm{PPI}=\text { patient and public involvement. } \\
\text { *For randomised studies, the following levels are possible: low, some concerns, high; for non-randomised studies, the following levels are } \\
\text { possible: low, moderate, serious, critical. These differences are due to differences in tools used to assess risk of bias. }\end{array}$} \\
\hline
\end{tabular}

Main meta-analysis (randomised studies only) We included seven randomised studies (eight PPI interventions) in our main meta-analysis. These interventions all consisted of patient or lay involvement in the design or delivery of patient information, with Ford et al's intervention also including recruitment sessions hosted by churches in the target community. ${ }^{46}$ Pooling the data from seven randomised studies in 


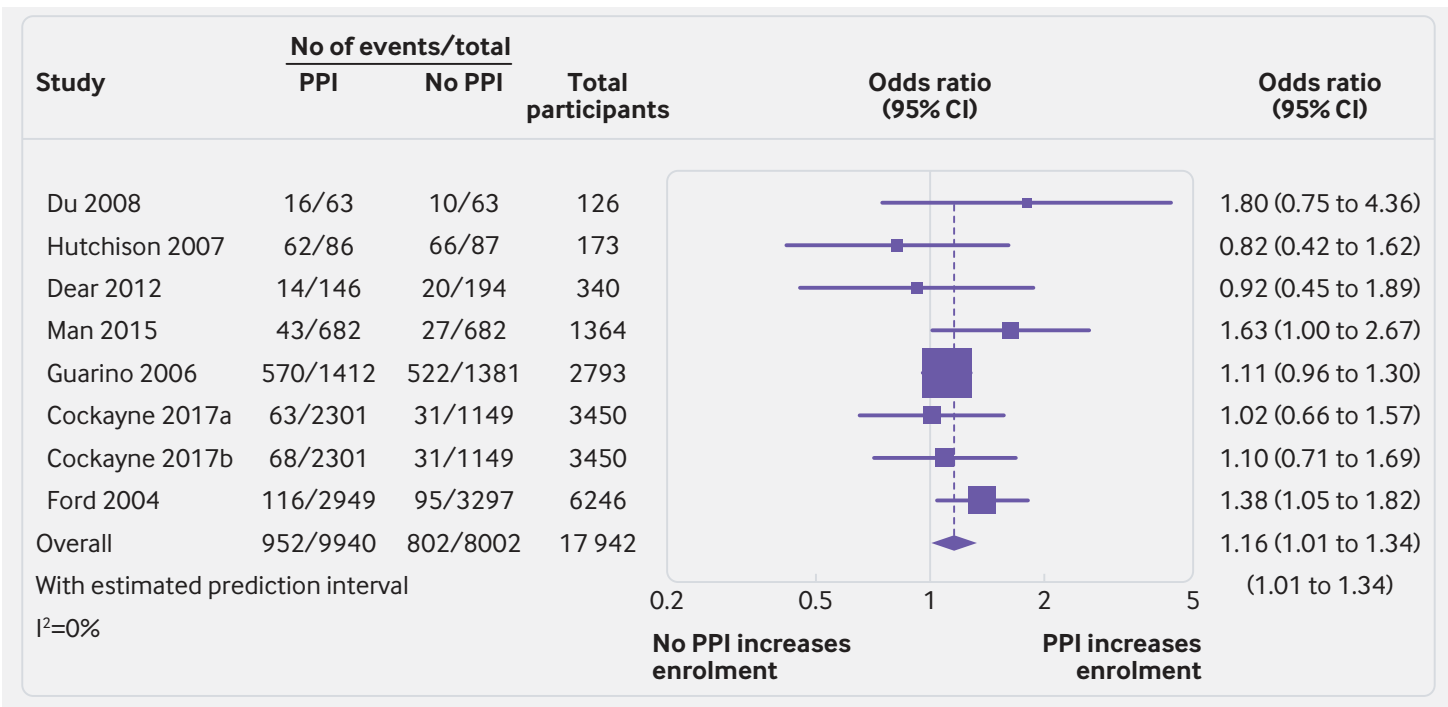

Fig 2 | Odds ratios for patient enrolment in clinical trial with versus without patient and public involvement (PPI) intervention (randomised studies only)

our main meta-analysis showed that, on average, PPI interventions modestly but significantly increased the odds of a patient enrolling in a clinical trial compared with no PPI (odds ratio 1.16, 1.01 to $1.34 ; \mathrm{P}=0.04$ ). We found low heterogeneity between studies $\left(\mathrm{I}^{2}=0.0 \%\right)$, yielding a $95 \%$ prediction interval of the odds ratio of 1.01 to 1.34 (fig 2).

\section{Secondary meta-analysis and subgroup analyses (randomised and non-randomise.d studies combined)}

Our secondary meta-analysis, combining 19 randomised and non-randomised studies (21 PPI interventions), also found that, on average, PPI interventions significantly increased the odds of a patient enrolling in a clinical trial compared with no PPI or non-PPI interventions (odds ratio $1.87,1.25$ to 2.80; $\mathrm{P}=0.004)$. We found substantial heterogeneity between studies $\left(\mathrm{I}^{2}=95.7 \%\right)$, yielding a 95\% prediction interval of the odds ratio of 0.36 to 9.86 (fig 3). Exploratory subgroup analyses showed that the overall positive association between PPI interventions and enrolment substantially increased when at least one involved person had lived experience of the health condition under study (odds ratio $3.14,1.89$ to 5.22 ) and all but disappeared when the involved people had no such lived experience $(1.07,0.74$ to 1.53$)$. Metaregression confirmed that this effect was statistically significant $(\mathrm{P}=0.02)$. Subgroup differences between any of the other variables explored (appendix 2), including trial intervention type (simple versus complex), the timing of involvement (designing recruitment and retention strategies versus developing patient-facing information versus direct recruitment or retention of participants), and enrolment rate denominator (before versus after eligibility screening), were not found to be statistically significant using meta-regression $(\mathrm{P}>0.3)$. Meta-regression was not able to explain the high between study heterogeneity, but it may be due in part to the diverse range of evaluation methods used and the high risk of bias by confounding in non-randomised studies. It could also be explained by heterogeneity of the PPI interventions: almost all of the PPI interventions in the high quality, randomised studies were aimed at improving patient information, whereas the more complex and more unusual interventions were largely evaluated using poorer quality observational or quasi-experimental methods.

\section{Sensitivity analyses and Peters' test}

The positive overall association between PPI interventions and enrolment remained statistically significant throughout all sensitivity analyses except when we excluded interventions with nonPPI components from the secondary analysis (see appendix 3). Although the estimated effect of PPI interventions actually increased in this analysis (odds ratio $=2.70$ ), the exclusion of 15/21 studies yielded a very wide $95 \%$ confidence interval (0.83 to 8.84$)$. We could not restrict this particular sensitivity analysis to randomised studies because this subsample included only one "pure" PPI intervention. ${ }^{49}$ Peters' test showed no evidence of bias due to small study effects $(\mathrm{P}=0.92$ for main analysis; $\mathrm{P}=0.59$ for secondary analysis).

\section{Cost effectiveness of PPI interventions}

Of the two studies reporting the cost per participant enrolled, MacEntee et al reported that a PPI strategy to recruit participants at community centres through a local contact person, although more effective, was more than twice the cost per participant of a non-PPI strategy that used postal invitations ( $\$ 23$ (£18; €20) $v \$ 11) .{ }^{60}$ Chlebowski et al reported that a PPI strategy to recruit trial participants via existing research participants was only one quarter the cost of a nonPPI strategy that used commercial mailing lists to send postal invitations ( $\$ 59 \vee \$ 259$ per participant enrolled). ${ }^{36}$ 


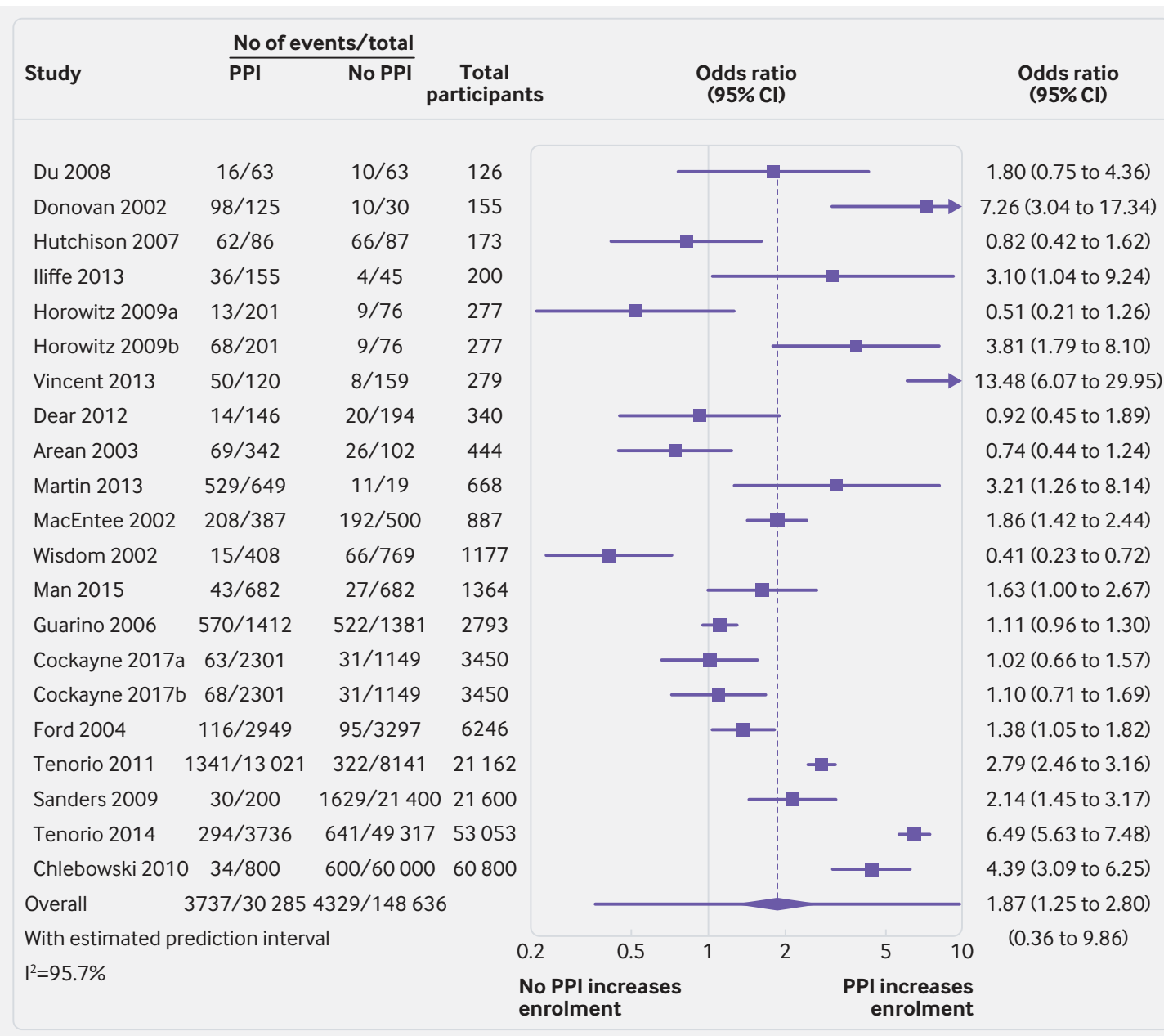

Fig 3 | Odds ratios for patient enrolment in clinical trial with patient and public involvement (PPI) intervention versus no PPI or non-PPI intervention (randomised and non-randomised studies combined)

\section{Impact of PPI interventions on retention}

Main meta-analysis (randomised studies only)

Pooling the data from three randomised studies (four PPI interventions) in our main meta-analysis did not show a statistically significant effect of PPI interventions on participant retention (odds ratio 1.16, 0.33 to 4.14; $\mathrm{P}=0.73$ ). Results varied widely across studies, with effect estimates ranging from odds ratios of 0.38 to $2.52\left(\mathrm{I}^{2}=83.5 \%\right.$; $95 \%$ prediction interval 0.06 to 22.37; appendix 4).

\section{Secondary meta-analysis (randomised and non-} randomised studies combined)

Our secondary meta-analysis, combining five randomised and non-randomised studies (six PPI interventions), also found no statistically significant effect of PPI interventions on participant retention, compared with no PPI or non-PPI interventions (odds ratio $1.20,0.52$ to $2.77 ; \mathrm{P}=0.59$ ). Again, we found substantial heterogeneity between studies $\left(\mathrm{I}^{2}=78.3 \%\right)$, yielding a $95 \%$ prediction interval of the odds ratio of 0.20 to 7.18 (forest plot in appendix 5). At the individual study level, only one PPI intervention was significantly associated with retention: this constituted use of lay community health advisers to support participants (the only PPI intervention specifically targeting retention), leading to a significant improvement in retention rates (odds ratio $2.52,1.82$ to 3.50$){ }^{47}$ Apart from this example, the PPI interventions primarily targeted enrolment, not retention. We did not do subgroup analyses for retention outcomes because of the small sample size.

\section{Sensitivity analyses and Peters' test}

Sensitivity analyses did not alter the findings (appendix 6), and Peters' test showed no evidence of bias due to small study effects $(\mathrm{P}=0.44$ for main analysis; $\mathrm{P}=0.41$ for secondary analysis).

\section{Discussion}

This review identified a variety of PPI interventions aimed at improving enrolment and retention of participants in clinical trials. Patients and lay members of the public were involved in designing recruitment and retention strategies and patient-facing information, identifying and approaching potential participants, and troubleshooting when recruitment was poor. We did not identify any studies that assessed the impact on enrolment or retention of PPI in developing the trial question or designing the trial itself. 
On average, PPI interventions significantly increased the odds of a patient enrolling in a clinical trial, relative to no PPI or non-PPI recruitment interventions. This remained statistically significant regardless of whether non-randomised studies were excluded or included, as well as in sensitivity analysis that removed studies at highest risk of bias. To illustrate what our main findings could mean in practice: in a hypothetical sample of 1000 patients, of which typically 100 enrol (consistent with the $10 \%$ average enrolment rate in our sample of studies), a PPI intervention similar to those included in our meta-analysis of randomised studies would likely lead to between one and 30 (average 14) extra patients being enrolled. As these PPI interventions were mostly restricted to patient or lay involvement in the design or delivery of patient information, the effect size might be even larger for PPI that begins at earlier stages of trial design, as the opportunity to influence patients' views and experiences would extend beyond just the provision of information.

A key exploratory finding was that the effect size was significantly greater when the people involved had lived experience of the health condition under study, compared with no such lived experience. This is consistent with the view that patients and carers can benefit research through their role as "expert in lived experience, ${ }^{80}$ although the precise mechanisms linking such expertise with improvements in enrolment and retention are unclear-something that we are exploring in a complementary realist analysis of the included studies. This finding, along with all other subgroup analysis and meta-regression findings, should be interpreted with caution owing to the potential for study level confounding.

Far fewer studies evaluated the impact of PPI interventions on retention of trial participants. They showed, on average, a modest but non-significant improvement in retention; the very wide $95 \%$ confidence intervals mean that we cannot rule out a potentially large increase or decrease in retention associated with PPI. None of the PPI interventions in the retention analysis included people with lived experience of the health condition under study, and most of them primarily targeted enrolment rather than retention.

\section{Strengths and limitations of review}

To our knowledge, this is the first attempt to combine data on the impact of PPI on enrolment and retention in health research, providing a quantitative summary and exploring the influence of contextual and intervention factors. Our results are consistent with previous observational studies that suggested an average positive association between PPI and success of recruitment in UK based health studies. ${ }^{15}{ }^{16}$ Unlike these previous studies, our review encompassed all geographies and clinical areas, and we were able to explore, to some extent, the influence of the characteristics and context of PPI.

Our review has several limitations. Most of the interventions included non-PPI components, and we could not separate out the effects of these from the effects of the PPI components. When interventions including non-PPI components were excluded in a sensitivity analysis of both randomised and nonrandomised studies combined, PPI was still associated with improved enrolment but with reduced certainty due to the decrease in sample size.

We were unable to explore the influence of many potentially important factors such as underlying programme theory, the fidelity and sustainability of interventions, the quality of relationships between involved patients and researchers, and the attitude of research leaders towards PPI. ${ }^{23}$ We are undertaking a realist analysis of the included papers to shed more light on these complexities. ${ }^{23}$ The framing of PPI as a complex intervention is itself controversial, ${ }^{82}$ but we believe that this approach, alongside a range of other perspectives, can usefully contribute to the much broader debate about the impact of PPI in health research.

Our 95\% prediction intervals should be interpreted with caution because prediction intervals have been reported to be less reliable in meta-analyses with unbalanced study sizes. ${ }^{83}$ Also, we were unable to provide a useful summary of the cost effectiveness of PPI, because very few studies included an economic impact assessment; thus an "effective" PPI intervention may not necessarily be cost effective. However, financial modelling of the impact of PPI in a typical oncology trial suggests that PPI interventions that improve enrolment may add considerable financial value. $^{84}$

Finally, the findings of this study say nothing about the quality or ethical acceptability of PPI in the included studies or patients' views on the importance of the clinical trials being conducted. PPI may improve enrolment, but this does not rule out negative effects such as an emotional cost to the people involved or patients feeling coerced into enrolling. ${ }^{85}$ Should patients assume that all trials are conducted for their benefit and automatically endorse every trial? Do (and should) involved patients have the necessary skills to assess the risks involved on behalf of their fellow patients? These are important dilemmas that are beyond the scope of this study.

\section{Implications for clinical trialists and PPI policy makers}

Our findings add support to the case for involving patients and carers in the design and conduct of clinical trials. In the UK, funding proposals and protocols for trials are often reviewed by institutional lay panels; our review suggests that, ideally, at least some of these reviewers would be patients and carers with lived experience of the health condition under study.

The apparent failure of some PPI interventions to improve enrolment and retention shows that many factors other than PPI also influence these outcomes. In addition, some PPI interventions in our review were one of several recruitment strategies used by clinical trialists and may not have been sufficient alone; for 
example, Sanders et al found that although their word of mouth PPI strategy was relatively effective at enrolling those it reached, it contributed only $2.2 \%$ of the total participants owing to limited reach (200 people), compared with $70.3 \%$ for the targeted mailout strategy (which reached 21400 people). ${ }^{67}$ PPI will not solve all recruitment and retention problems, and clinical trialists would be wise to implement multiple additional strategies to minimise the risk of poor enrolment and retention. Furthermore, involving patients in the early stages of trial development can sometimes lead researchers to abandon the whole idea of the trial, ${ }^{86}$ suggesting that if the target patients are not convinced that the trial question is worth answering, PPI in later stages of the trial (such as those seen in this review) may be futile.

\section{Unanswered questions and future research}

Well planned, high quality evaluations are needed to improve our understanding of the impact of PPI on enrolment and retention in clinical trials. In particular: which types of PPI work best in particular settings and contexts; the mechanisms underlying the impact of PPI on enrolment and retention; the cost effectiveness of PPI interventions (an important part of the drive to improve trial efficiency); the impact of PPI interventions specifically targeting retention (which has received very little attention relative to enrolment); and the impact of PPI at the early stages of trial proposal and design.

We are grateful to Michael Osborne (patient contributor), Shaun Treweek, and Louise Locock (University of Aberdeen) for providing expert advice throughout this study; Ben Feakins (medical statistician, University of Oxford) for providing statistical advice at an early stage of this review; Rebecca Harmston (patient contributor) for contributing to the analysis plan and interpretation of results; and Trish Greenhalgh (NIHR Oxford BRC theme leader, Partnerships for Health Wealth and Innovation) for providing helpful feedback on an early draft of this paper. Contributors: JCC, AC, SPZ, DE, and SR conceived and designed this review. JCC, IRC, and AP undertook searches, record screening, and data extraction (supervised by JCC). JH wrote the code for and ran the meta-analyses in Stata. All authors contributed to interpretation of the results. JCC wrote the manuscript, and all authors commented on the draft and approved the final version. The corresponding author attests that all listed authors meet authorship criteria and that no others meeting the criteria have been omitted. JCC is the guarantor.

Funding: JC, SPZ, and JH were supported by the National Institute for Health Research (NIHR) Oxford Biomedical Research Centre (BRC). IRC was supported by the University of Oxford Returning Carers Fund. The funders were not involved in the study design; data collection, analysis, or interpretation; or writing the report. All authors had full access to all of the data in the study and can take responsibility for the integrity of the data and accuracy of the data analysis. The views expressed are those of the authors and not necessarily those of the NHS, the NIHR, or the Department of Health and Social Care.

Competing interests: All authors have completed the ICMJE uniform disclosure form at www.icmje.org/coi_disclosure.pdf (available on request from the corresponding author) and declare: no support from any organisation for the submitted work other than that described above; no financial relationships with any organisations that might have an interest in the submitted work in the previous three years; no other relationships or activities that could appear to have influenced the submitted work.

Ethical approval: Not needed.

Data sharing: The dataset is available on request from the corresponding author.

Transparency declaration: The lead author (study guarantor) affirms that this manuscript is an honest, accurate, and transparent account of the study being reported; that no important aspects of the study have been omitted; and that any discrepancies from the study as planned (and, if relevant, registered) have been explained.

This is an Open Access article distributed in accordance with the terms of the Creative Commons Attribution (CC BY 4.0) license, which permits others to distribute, remix, adapt and build upon this work, for commercial use, provided the original work is properly cited. See: http://creativecommons.org/licenses/by/4.0/.

1 Al-Shahi Salman R, Beller E, Kagan J, et al. Increasing value and reducing waste in biomedical research regulation and management. Lancet 2014;383:176-85. doi:10.1016/S0140-6736(13)62297-7

2 Treweek S, Lockhart P, Pitkethly M, et al. Methods to improve recruitment to randomised controlled trials: Cochrane systematic review and meta-analysis. BMJ Open 2013;3:e002360. doi:10.1136/bmjopen-2012-002360

3 Duley L, Gillman A, Duggan M, et al. What are the main inefficiencies in trial conduct: a survey of UKCRC registered clinical trials units in the UK. Trials 2018;19:15. doi:10.1186/s13063-017-2378-5

4 Tudur Smith C, Hickey H, Clarke M, Blazeby J, Williamson P. The trials methodological research agenda: results from a priority setting exercise. Trials 2014;15:32. doi:10.1186/1745-6215-15-32

5 Walters SJ, Bonacho Dos Anjos Henriques-Cadby I, Bortolami O, et al. Recruitment and retention of participants in randomised controlled trials: a review of trials funded and published by the United Kingdom Health Technology Assessment Programme. BMJ Open 2017;7:e015276. doi:10.1136/bmjopen-2016-015276

6 Sully BG, Julious SA, Nicholl J. A reinvestigation of recruitment to randomised, controlled, multicenter trials: a review of trials funded by two UK funding agencies. Trials 2013;14:166. doi:10.1186/1745-6215-14-166

7 Bower P, Rick J. Systematic Techniques for Assisting Recruitment to Trials (START): a study of the feasibility of testing recruitment interventions by nesting across multiple trials in primary care and community settings. 2013. http://www.population-health. manchester.ac.uk/mrcstart/.

8 Treweek S, Altman DG, Bower P, et al. Making randomised trials more efficient: report of the first meeting to discuss the Trial Forge platform. Trials 2015;16:261. doi:10.1186/s13063-015-0776-0

9 Bower P, Brueton V, Gamble C, et al. Interventions to improve recruitment and retention in clinical trials: a survey and workshop to assess current practice and future priorities. Trials 2014;15:399. doi:10.1186/1745-6215-15-399

10 INVOLVE. What is public involvement in research? 2015. http:// www.invo.org.uk/find-out-more/what-is-public-involvement-inresearch-2/.

11 National Institute for Health Research. Patient and public involvement in health and social care research: a handbook for researchers. 2014. https://www.nihr.ac.uk/about-us/CCF/funding/how-we-canhelp-you/RDS-PPI-Handbook-2014-v8-FINAL.pdf.

12 Price A, Albarqouni L, Kirkpatrick J, et al. Patient and public involvement in the design of clinical trials: An overview of systematic reviews. J Eval Clin Pract 2018;24:240-53. doi:10.1111/jep.12805

13 Ennis L, Wykes T. Impact of patient involvement in mental health research: longitudinal study. Br J Psychiatry 2013;203:381-6. doi:10.1192/bjp.bp.112.119818

14 Boote J, Baird W, Sutton A. Public involvement in the design and conduct of clinical trials: a review. Int I Interdiscip Soc Sci Annu Rev 2011;5:91-112. doi:10.18848/1833-1882/CGP/ v05i11/59313

15 Brett J, Staniszewska S, Mockford C, et al. Mapping the impact of patient and public involvement on health and social care research: a systematic review. Health Expect 2014;17:637-50. doi:10.1111/ j.1369-7625.2012.00795.x

16 Staley K. Exploring impact: public involvement in NHS, public health and social care research. INVOLVE, 2009.

17 McDonald AM, Knight RC, Campbell MK, et al. What influences recruitment to randomised controlled trials? A review of trials funded by two UK funding agencies. Trials 2006;7:9. doi:10.1186/1745-6215-7-9

18 Kearney A, Williamson P, Young B, et al. Priorities for methodological research on patient and public involvement in clinical trials: A modified Delphi process. Health Expect 2017;20:1401-10. doi:10.1111/hex.12583

19 Liberati A, Altman DG, Tetzlaff,, et al. The PRISMA statement for reporting systematic reviews and meta-analyses of studies that evaluate healthcare interventions: explanation and elaboration. BMJ 2009;339:b2700. doi:10.1136/bmj.b2700

20 INVOLVE. Evidence Library. 2016. http://www.invo.org.uk/resourcecentre/libraries/evidence-library/.

21 Medical Research Council. Developing and evaluating complex interventions: new guidance. MRC, 2008.

22 World Health Organization. International Clinical Trials Registry Platform: Glossary. 2018. http://www.who.int/ictrp/glossary/en/. 
23 Shepperd S, Lewin S, Straus S, et al. Can we systematically review studies that evaluate complex interventions? PLoS Med 2009;6:e1000086. doi:10.1371/journal.pmed.1000086

24 Higgins JP, Altman DG, Gøtzsche PC, et al, Cochrane Bias Methods Group, Cochrane Statistical Methods Group. The Cochrane Collaboration's tool for assessing risk of bias in randomised trials. BMJ 2011;343:d5928. doi:10.1136/bmj.d5928

25 Sterne JA, Hernán MA, Reeves BC, et al. ROBINS-I: a tool for assessing risk of bias in non-randomised studies of interventions. BM/ 2016;355:i4919. doi:10.1136/bmj.i4919

26 Higgins JPT. Commentary: Heterogeneity in meta-analysis should be expected and appropriately quantified. Int Epidemiol 2008;37:1158-60. doi:10.1093/ije/dyn204

27 Cornell JE, Mulrow CD, Localio R, et al. Random-effects meta-analysis of inconsistent effects: a time for change. Ann Intern Med 2014;160:267-70. doi:10.7326/M13-2886

28 Röver C, Knapp G, Friede T. Hartung-Knapp-Sidik-Jonkman approach and its modification for random-effects meta-analysis with few studies. BMC Med Res Methodol 2015;15:99. doi:10.1186/s12874-015-0091-1

29 Hartung J, Knapp G. A refined method for the meta-analysis of controlled clinical trials with binary outcome. Stat Med 2001;20:3875-89. doi:10.1002/sim.1009

30 Riley RD, Higgins JPT, Deeks JJ. Interpretation of random effects meta-analyses. BMJ 2011;342:d549. doi:10.1136/bmj.d549

31 Higgins JP, Thompson SG, Spiegelhalter DJ. A re-evaluation of random-effects meta-analysis. I R Stat Soc Ser A Stat Soc 2009;172:137-59. doi:10.1111/j.1467-985X.2008.00552.x

32 Peters IL, Sutton AJ, Jones DR, Abrams KR, Rushton L. Comparison of two methods to detect publication bias in meta-analysis. JAMA 2006;295:676-80. doi:10.1001/jama.295.6.676

33 Sterne IA, Sutton AJ, loannidis IP, et al. Recommendation for examining and interpreting funnel plot asymmetry in meta-analyses of randomised controlled trials. BMJ 2011;343:d4002. doi:10.1136/bmi.d4002

34 Areán PA, Alvidrez J, Nery R, Estes C, Linkins K. Recruitment and retention of older minorities in mental health services research Gerontologist 2003:43:36-44. doi:10.1093/geront/43.1.36

35 Areán PA, Gum A, McCulloch CE, Bostrom A, Gallagher-Thompson D, Thompson L. Treatment of depression in low-income older adults. Psychol Aging 2005;20:601-9. doi:10.1037/0882-7974.20.4.601

36 Chlebowski RT, Menon R, Chaisanguanthum RM, Jackson DM. Prospective evaluation of two recruitment strategies for a randomized controlled cancer prevention trial. Clin Trials 2010;7:744-8. doi:10.1177/1740774510383886

37 Klein EA, Thompson IM, Lippman SM, et al. SELECT: the next prostate cancer prevention trial. Selenum and Vitamin $\mathrm{E}$ Cancer Prevention Trial. J Urol 2001;166:1311-5. doi:10.1016/S0022-5347(05)65759-X

38 Lippman SM, Klein EA, Goodman PJ, et al. Effect of selenium and vitamin $\mathrm{E}$ on risk of prostate cancer and other cancers: the Selenium and Vitamin E Cancer Prevention Trial (SELECT). JAMA 2009;301:39-51. doi:10.1001/jama.2008.864

39 Cockayne S, Fairhurst C, Adamson J, et al. An optimised patient information sheet did not significantly increase recruitment or retention in a falls prevention study: an embedded randomised recruitment trial. Trials 2017;18:144 doi:10.1186/s13063-017-1797-7

40 Cockayne S, Adamson J, Clarke A, et al, REFORM study. Cohort Randomised Controlled Trial of a Multifaceted Podiatry Intervention for the Prevention of Falls in Older People (The REFORM Trial). PLoS One 2017;12:e0168712. doi:10.1371/journal.pone.0168712

41 Dear RF, Barratt AL, Askie LM, et al. Impact of a cancer clinical trials web site on discussions about trial participation: a cluste randomized trial. Ann Oncol 2012;23:1912-8. doi:10.1093/ annonc/mdr585

42 Dear R, Barratt A, Askie L, et al. Adding value to clinical trial registries: insights from Australian Cancer Trials Online, a website for consumers. Clin Trials 2011;8:70-6. doi:10.1177/1740774510392392

43 Donovan J, Mills N, Smith M, et al. Quality improvement report: Improving design and conduct of randomised trials by embedding them in qualitative research: ProtecT (prostate testing for cancer and treatment) study. Commentary: presenting unbiased information to patients can be difficult. BM/ 2002;325:766-70. doi:10.1136/bmi.325.7367.766

44 Donovan J, Hamdy F, Neal D, et al, ProtecT Study Group. Prostate Testing for Cancer and Treatment (ProtecT) feasibility study. Health Technol Assess 2003;7:1-88. doi:10.3310/hta7140

45 Du W, Mood D, Gadgeel S, Simon MS. An educational video to increase clinical trials enrollment among lung cancer patients. J Thorac Oncol 2008;3:23-9. doi:10.1097/ JTO.0b013e31815e8bb2
46 Ford ME, Havstad SL, Davis SD. A randomized trial of recruitment methods for older African American men in the Prostate, Lung, Colorectal and Ovarian (PLCO) Cancer Screening Trial. Clin Trials 2004;1:343-51. doi:10.1191/1740774504cn029oa

47 Fouad MN, Johnson RE, Nagy MC, Person SD, Partridge EE. Adherence and retention in clinical trials: a community-based approach. Cancer 2014;120(Suppl 7):1106-12. doi:10.1002/cncr.28572

48 ASCUS-LSIL Traige Study (ALTS) Group. Results of a randomized trial on the management of cytology interpretations of atypical squamous cells of undetermined significance. $A m$ J Obstet Gynecol 2003;188:1383-92. doi:10.1016/S00029378(03)00418-6

49 Guarino P, Elbourne D, Carpenter J, Peduzzi P. Consumer involvement in consent document development: a multicenter cluster randomized trial to assess study participants' understanding. Clin Trials 2006;3:19-30. doi:10.1191/1740774506cn1330a

50 Donta ST, Clauw DJ, Engel CC. Jr, et al, VA Cooperative Study \#470 Study Group. Cognitive behavioral therapy and aerobic exercise for Gulf War veterans' illnesses: a randomized controlled trial. JAMA 2003;289:1396-404. doi:10.1001/jama.289.11.1396

51 Horowitz CR, Brenner BL, Lachapelle S, Amara DA, Arniella G. Effective recruitment of minority populations through communityled strategies. Am J Prev Med 2009;37(Suppl 1):S195-200. doi:10.1016/j.amepre.2009.08.006

52 Parikh P, Simon EP, Fei K, Looker H, Goytia C, Horowitz CR. Results of a pilot diabetes prevention intervention in East Harlem, New York City: Project HEED. Am J Public Health 2010;100(Suppl 1):S232-9. doi:10.2105/AJPH.2009.170910

53 Hutchison C, Cowan C, McMahon T, Paul J. A randomised controlled study of an audiovisual patient information intervention on informed consent and recruitment to cancer clinical trials. $\mathrm{Br}$ Cancer 2007;97:705-11. doi:10.1038/sj.bjc.6603943

54 Hutchison C, McCreaddie M. The process of developing audiovisual patient information: challenges and opportunities. J Clin Nurs 2007;16:2047-55 doi:10.1111/j.1365-2702.2006.01758.x

55 Iliffe S, McGrath T, Mitchell D. The impact of patient and public involvement in the work of the Dementias \& Neurodegenerative Diseases Research Network (DeNDRoN): case studies. Health Expect 2013;16:351-61. doi:10.1111/j.1369-7625.2011.00728.x

56 Jones R, Sheehan B, Phillips P, et al, DOMINO-AD team. DOMINO$A D$ protocol: donepezil and memantine in moderate to severe Alzheimer's disease - a multicentre RCT. Trials 2009;10:57. doi:10.1186/1745-6215-10-57

57 Howard R, McShane R, Lindesay J, et al. Donepezil and memantine for moderate-to-severe Alzheimer's disease. $N$ Engl Med 2012;366:893-903. doi:10.1056/NEJMoa1106668

58 Kass NE, Sugarman J, Medley AM, et al. An intervention to improve cancer patients' understanding of early-phase clinical trials. IRB 2009;31:1-10.

59 Kimmick GG, Peterson BL, Kornblith AB, et al. Improving accrual of older persons to cancer treatment trials: a randomized trial comparing an educational intervention with standard information: CALGB 360001. J Clin Oncol 2005;23:2201-7. doi:10.1200/ ICO.2005.01.222

60 MacEntee MI, Wyatt C, Kiyak HA, et al. Response to direct and indirect recruitment for a randomised dental clinical trial in a multicultural population of elders. Community Dent Oral Epidemiol 2002;30:377 81. doi:10.1034/j.1600-0528.2002.00003.x

61 Man MS, Rick J, Bower P, Healthlines Study Group, MRC-START Group. Improving recruitment to a study of telehealth management for long-term conditions in primary care: two embedded, randomised controlled trials of optimised patient information materials. Trials 2015:16:309 doi:10.1186/s13063-015-0820-0

62 Thomas CL, Man M-S, O'Cathain A, et al. Effectiveness and cost-effectiveness of a telehealth intervention to support the management of long-term conditions: study protocol for two linked randomized controlled trials. Trials 2014;15:36. doi:10.1186/1745-6215-15-36

63 Martin A, Negron R, Balbierz A, Bickell N, Howell EA. Recruitment of black and Latina women to a randomized controlled trial. J Health Care Poor Underserved 2013;24:1102-14. doi:10.1353/hpu.2013.0125

64 Howell EA, Balbierz A, Wang J, Parides M, Zlotnick C, Leventhal H. Reducing postpartum depressive symptoms among black and Latina mothers: a randomized controlled trial. Obstet Gynecol 2012;119:942-9. doi:10.1097/AOG.0b013e318250ba48

65 Moinpour CM, Atkinson JO, Thomas SM, et al. Minority recruitment in the prostate cancer prevention trial. Ann Epidemiol 2000;10(Suppl):S85-91. doi:10.1016/S10472797(00)00185-X

66 Porter M, Ramaswamy B, Beisler K, et al. A Comprehensive Program for the Enhancement of Accrual to Clinical Trials. Ann Surg Oncol 2016;23:2146-52. doi:10.1245/s10434-016-5091-9 
67 Sanders KM, Stuart AL, Merriman EN, et al. Trials and tribulations of recruiting 2,000 older women onto a clinical trial investigating falls and fractures: Vital D study. BMC Med Res Methodol 2009;9:78 doi:10.1186/1471-2288-9-78

68 Sanders KM, Stuart AL, Williamson EJ, et al. Annual high-dose oral vitamin D and falls and fractures in older women: a randomized controlled trial. JAMA 2010;303:1815-22. doi:10.1001/ jama.2010.594

69 Tenorio SL, Gamito El, Ogden S, et al. A special program to increase the participation of Hispanics in the Prostate, Lung, Colorectal, and Ovarian [PLCO) Cancer Screening Trial. Hisp Health Care Int 2011:9:13-21. doi:10.1891/1540-4153.9.1.13.

70 Prorok PC, Andriole GL, Bresalier RS, et al, Prostate, Lung, Colorectal and Ovarian Cancer Screening Trial Project Team. Design of the Prostate, Lung, Colorectal and Ovarian (PLCO) Cancer Screening Trial. Control Clin Trials 2000;21(Suppl):273S-309S doi:10.1016/S0197-2456(00)00098-2

71 Simpson NK, Johnson CC, Ogden SL, et al, Prostate, Lung, Colorectal and Ovarian Cancer Screening Trial Project Team. Recruitment strategies in the Prostate, Lung, Colorectal and Ovarian (PLCO) Cancer Screening Trial: the first six years. Control Clin Trials 2000;21(Suppl):356S-78S. doi:10.1016/S01972456(00)00102-1

72 Tenorio SL, O’Donnell Cl, Hernandez J, Rozjabek HM, Lynch D, Marcus PM. Culturally sensitive approaches to recruitment and retention of Hispanics in the national lung screening trial. / Immigr Minor Health 2014;16:761-4. doi:10.1007/s10903-013-9862-0

73 Aberle DR, Adams AM, Berg CD, et al, National Lung Screening Trial Research Team. Baseline characteristics of participants in the randomized national lung screening trial. J Natl Cancer Inst 2010;102:1771-9. doi:10.1093/jnci/djq434

74 Aberle DR, Adams AM, Berg CD, et al, National Lung Screening Trial Research Team. Reduced lung-cancer mortality with low-dose computed tomographic screening. N Engl J Med 2011;365:395-409. doi:10.1056/NEJMoa1102873

75 Vicini F, Nancarrow-Tull J, Shah C, et al. Increasing accrual in cancer clinical trials with a focus on minority enrollment: The William Beaumont Hospital Community Clinical Oncology Program Experience. Cancer 2011:117:4764-71. doi:10.1002/cncr.26094

76 Vincent D, McEwen MM, Hepworth JT, Stump CS. Challenges and success of recruiting and retention for a culturally tailored diabetes prevention program for adults of Mexican descent. Diabetes Educ 2013·39:222-30. doi:10.1177/0145721713475842
77 Vincent D, McEwen MM, Hepworth JT, Stump CS. The effects of a community-based, culturally tailored diabetes prevention intervention for high-risk adults of Mexican descent. Diabetes Educ 2014;40:202-13. doi:10.1177/0145721714521020

78 Wallace K, Fleshner N, Jewett M, Basiuk J, Crook J. Impact of a multidisciplinary patient education session on accrual to a difficult clinical trial: the Toronto experience with the surgical prostatectomy versus interstitial radiation intervention trial. J Clin Oncol 2006;24:4158-62. doi:10.1200/JCO.2006.06.3875

79 Wisdom K, Neighbors K, Williams VH, Havstad SL, Tilley BC. Recruitment of African Americans with type 2 diabetes to a randomized controlled trial using three sources. Ethn Health 2002;7:267-78. doi:10.1080/1355785022000060727

80 Crocker JC, Boylan A-M, Bostock J, Locock L. Is it worth it? Patient and public views on the impact of their involvement in health research and its assessment: a UK-based qualitative interview study. Health Expect 2017;20:519-28. doi:10.1111/hex.12479

81 Evans D, Coad J, Cottrell K, et al. Public involvement in research: assessing impact through a realist evaluation. Health Services and Delivery Research 2014;2. doi:10.3310/hsdr02360

82 Edelman N, Barron D. Evaluation of public involvement in research: time for a major re-think? J Health Serv Res Policy 2016;21:209-11. doi:10.1177/1355819615612510

83 Partlett C, Riley RD. Random effects meta-analysis: Coverage performance of $95 \%$ confidence and prediction intervals following REML estimation. Stat Med 2017:36:301-17. doi:10.1002/sim.7140

84 Levitan B, Getz K, Eisenstein EL, et al. Assessing the Financial Value of Patient Engagement: A Quantitative Approach from CTTI's Patient Groups and Clinical Trials Project. Ther Innov Regul Sci 2018;52:220-9. doi:10.1177/2168479017716715

85 Health Experiences Research Group. Patient and public involvement in research. 2014. http://www.healthtalk.org/peoples-experiences/ medical-research/patient-and-public-involvement-research/topics.

86 Boote JD, Dalgleish M, Freeman J, Jones Z, Miles M, Rodgers H. 'But is it a question worth asking?' A reflective case study describing how public involvement can lead to researchers' ideas being abandoned. Health Expect 2014;17:440-51. doi:10.1111/j.1369-7625.2012.00771x

\section{Appendix 1-6}

